\title{
Mathematical modeling and performance analysis of an integrated solar heating and cooling system driven by parabolic trough collector and double-effect absorption \\ chiller
}

Xuejing Zheng ${ }^{1,2}$, Rui Shi ${ }^{1}$, Yaran Wang ${ }^{1,2,{ }^{*}}$, Shijun You ${ }^{1,2}$, Huan Zhang ${ }^{1,2}$, Junbao Xia ${ }^{3}$, Shen $\mathrm{Wei}^{4}$

${ }^{1}$ School of Environmental Science and Engineering, Tianjin University, Tianjin 300350, China.

${ }^{2}$ Key Laboratory of Efficient Utilization of Low and Medium Grade Energy (Tianjin University), Ministry of Education of China, Tianjin 300350, China.

${ }^{3}$ Science and Technology on Reactor System Design Technology Laboratory, Nuclear Power Institute of China, Chengdu 610213, Sichuan, China.

${ }^{4}$ The Bartlett School of Construction and Project Management, University College London (UCL), 1-19 Torrington Place, London WC1E 7HB, United Kingdom.

${ }^{*}$ Corresponding author: Tel./Fax: +86 2227400832. E-mail addresses: yaran_wang@tju.edu.cn.

Abstract:

With the increasing concerns on energy conservation and environmental protection, solar heating and cooling (SHC) system represents an attractive candidate in building sector. In this paper, an integrated SHC system driven by parabolic trough collector (PTC) and double-effect $\mathrm{H}_{2} \mathrm{O} / \mathrm{LiBr}$ absorption chiller was presented. The energy generated by solar collectors was supplied to the absorption chiller during the cooling period, and was directly used for space heating with the integration of plate heat exchanger during the heating period. The mathematical models of the whole system 
including the collector, the double-effect absorption chiller and the plate heat exchanger were established and were validated by field tests. Based on the proposed models, comparison of the SHC system and the conventional gas-driven absorption heating and cooling system was carried out by case study. The annual performances as well as energetic, economic and environmental assessments of the proposed system were investigated. Results show that, $21.3 \%$ of the primary energy consumption and $18.8 \%$ of the $\mathrm{CO}_{2}$ emission can be reduced in SHC system. Therefore, the proposed integrated solar heating and cooling system has a promising application prospect in sustainable development in view of its considerable energy saving benefits, potential economic viability and environmental friendly characteristics.

\section{Keywords:}

Solar Heating and Cooling; Double-effect Absorption Refrigeration; Parabolic Trough Collector; Energetic, Economic and Environmental (3E) assessment 


\section{Nomenclature}

\begin{tabular}{|c|c|}
\hline$a$ & solution circulation ratio $[\mathrm{kg} / \mathrm{kg}]$ \\
\hline$A$ & annual operating cost [RMB] \\
\hline$b$ & constant matrix \\
\hline$c_{p}$ & specific heat $[\mathrm{J} / \mathrm{kg} \cdot \mathrm{K}]$ \\
\hline$C$ & initial cost [RMB] \\
\hline$C D E$ & carbon dioxide emission [ton] \\
\hline COP & coefficient of performance \\
\hline$d$ & diameter $[\mathrm{m}]$ \\
\hline$D$ & refrigerant mass flow rate $[\mathrm{kg} / \mathrm{s}]$ \\
\hline$E$ & annual energy consumption [kWh] \\
\hline$E F$ & $\mathrm{CO}_{2}$ emission factor \\
\hline$f$ & focal distance $[\mathrm{m}]$ \\
\hline$F$ & area $\left[\mathrm{m}^{2}\right]$ \\
\hline$G$ & flow rate $(\mathrm{kg} / \mathrm{s})$ \\
\hline$h$ & convective heat transfer coefficient $\left[\mathrm{W} / \mathrm{m}^{2} \cdot \mathrm{K}\right]$ \\
\hline$H$ & enthalpy $[\mathrm{J}]$ \\
\hline$I$ & direct normal irradiance $\left[\mathrm{W} / \mathrm{m}^{2}\right]$ \\
\hline$K$ & heat transfer coefficient $\left[\mathrm{W} / \mathrm{m}^{2} \cdot \mathrm{K}\right]$ \\
\hline$l$ & length $[\mathrm{m}]$ \\
\hline$M$ & coefficient matrix \\
\hline$P B P$ & static payback period [year] \\
\hline$P E C$ & primary energy consumption [MWh] \\
\hline$P E F$ & primary energy factor \\
\hline PER & primary energy ratio \\
\hline PES & primary energy saving [MWh] \\
\hline$Q$ & heat transfer [W] \\
\hline$R$ & fouling resistance $\left[\mathrm{m}^{2} \cdot \mathrm{K} / \mathrm{W}\right]$ \\
\hline$S$ & solar irradiation absorption [W] \\
\hline$\Delta T$ & temperature difference $[\mathrm{K}]$ \\
\hline$T$ & temperature $[\mathrm{K}]$ \\
\hline$u$ & velocity $[\mathrm{m} / \mathrm{s}]$ \\
\hline$W$ & width $[\mathrm{m}]$ \\
\hline$x$ & concentration of the solution $[\%]$ \\
\hline$y$ & steam production ratio $[\mathrm{kg} / \mathrm{kg}]$ \\
\hline \multicolumn{2}{|c|}{ Greek symbols } \\
\hline$\eta$ & intercept factor \\
\hline
\end{tabular}




\begin{tabular}{|c|c|}
\hline$\eta_{I A M}$ & incidence angle modifier \\
\hline$\eta_{\text {end }}$ & geometrical end loss \\
\hline$\alpha$ & absorptivity \\
\hline$\rho$ & reflectivity \\
\hline$\varepsilon$ & emissivity \\
\hline$\tau$ & transmittance \\
\hline$\sigma$ & Stefan-Boltzmann constant $\left[\mathrm{W} / \mathrm{m}^{2} \cdot \mathrm{K}^{4}\right]$ \\
\hline$\theta$ & incidence angle $\left[{ }^{\circ}\right.$ ] \\
\hline$\lambda$ & heat conductivity coefficient $[\mathrm{W} / \mathrm{m} \cdot \mathrm{K}]$ \\
\hline$v$ & density $\left[\mathrm{kg} / \mathrm{m}^{3}\right]$ \\
\hline$\psi_{b}$ & burner combustion ratio [\%] \\
\hline$\xi$ & efficiency \\
\hline$\delta$ & thickness $[\mathrm{m}]$ \\
\hline \multicolumn{2}{|c|}{ Subscripts } \\
\hline a & ambient environment \\
\hline A & absorber \\
\hline $\mathrm{c}$ & collector \\
\hline cap & heating/cooling capacity \\
\hline $\mathrm{ch}$ & chilled water \\
\hline conv & convection \\
\hline $\mathrm{cw}$ & cooling water \\
\hline ex & external \\
\hline $\mathrm{E}$ & electricity \\
\hline $\mathrm{f}$ & heat transfer fluid \\
\hline $\mathrm{g}$ & glass envelope \\
\hline $\mathrm{h}$ & strong solution \\
\hline hex & high temperature heat exchanger \\
\hline hpg & high pressure generator \\
\hline hw & hot water \\
\hline in & internal \\
\hline int & inlet \\
\hline $\mathrm{k}$ & condenser \\
\hline 1 & weak solution \\
\hline lex & low temperature heat exchanger \\
\hline $\mathrm{LiBr}$ & lithium bromide solution \\
\hline $\operatorname{lpg}$ & low pressure generator \\
\hline
\end{tabular}




\begin{tabular}{|ll|}
\hline m & medium strong solution \\
out & natural gas \\
r & outlet \\
rad & receiver tube \\
re & radiation \\
ref & refrigerant \\
sky & reference \\
0 & sky \\
$1,2, \ldots, 15$ & evaporator \\
Abbreviations & state point \\
ABS & absorber \\
CON & condenser \\
EVA & evaporator \\
3E & energetic, economic and environmental \\
GHC & gas-driven absorption heating and cooling \\
HEX & high temperature heat exchanger \\
HPG & high pressure generator \\
LEX & low temperature heat exchanger \\
LPG & low pressure generator \\
PHE & plate heat exchanger \\
PTC & parabolic trough collector \\
SHC & solar heating and cooling \\
\hline
\end{tabular}




\section{$1 \quad$ 1. Introduction}

The use of conventional air conditioning system based on vapor compression

3 chillers dominates nearly $50 \%$ of the primary energy consumption and accounts for

4 about $40 \%$ of greenhouse gas emission in building sectors [1,2]. Research on energy

5 saving and environment benign alternatives for air conditioning has become a global

6 priority [3]. Of the many potential renewable solutions, solar heating and cooling (SHC)

7 system represents an attractive candidate for the merits of energy efficiency

8 enhancement and negligible environmental impact [4].

9 In SHC systems, the thermal energy generated by solar collectors may be directly

10 used for space heating, producing domestic hot water or supplied to absorption chillers

11 for cooling $[5,6]$. To ensure continuous and stable operation of the system, thermal

12 energy storage system or back-up energy source is usually considered [7].

13 For direct heating utilization, solar water heating system is widely accepted with

14 the advantages of mature technology based and low life cycle cost [8]. Depending on

15 whether the hot water is heated in the solar collectors or in a heat exchanger, direct

16 system and indirect system can be defined. Benefiting from the separation of the solar

17 collector loop and hot water loop, the indirect system can operate when the ambient

18 temperature is under $0^{\circ} \mathrm{C}[9]$.

19 For cooling energy production, the integration of solar thermal collector with

20 absorption chiller has attained a significant attention, due to its reliability and high

21 efficiency $[10,11]$. The most common working fluid pairs are water-lithium bromide 
$22\left(\mathrm{H}_{2} \mathrm{O}-\mathrm{LiBr}\right)$ for temperature levels greater than $4^{\circ} \mathrm{C}$ such as for air-conditioning

23 applications, and ammonia-water $\left(\mathrm{NH}_{3}-\mathrm{H}_{2} \mathrm{O}\right)$ for producing cooling in extremely low-

24 temperature levels such as for refrigeration purpose and industrial application [12,13].

25 The types of absorption chillers are classified on the basis of their thermodynamic cycle

26 of operation [14]. The advantages of moving toward a higher effect cycle are to enhance

27 the coefficient of performance (COP) of the chiller and to potentially save collector area,

28 if a high temperature heat source is available [15]. The COP of the single-effect chillers

29 is limited to around 0.7 with the driving heat source temperature around $80 \sim 100^{\circ} \mathrm{C}$.

30 Benefiting from two cascading generators, the COP of double-effect absorption chiller

31 can reach up to 1.42 , while the required driving temperature is around $150 \sim 200^{\circ} \mathrm{C}$ [16].

32 The types of the employed solar thermal collectors critically depend on the number of

33 effects. Among the various types of thermal collectors driving double-effect absorption

34 chillers, parabolic trough collector (PTC) has a considerable solar fraction and a

35 satisfactory thermal efficiency due to high concentration ratio (around 15 50) and low

36 heat loss levels [17]. The optimistic application potential of PTC to feed double-effect

37 absorption chillers has been pointed out and summarized by Cabrera et al.[18].

The solar-assisted single-effect absorption refrigeration has been extensively

39 studied $[19,20]$. Numerous experimental analysis and simulation studies have been

40 conducted with regard to parametric optimization [21], performance improvement [22],

41 thermal energy storage [23], auxiliary energy alternative [24], energetic [25] and

42 economic analysis [26] etc. The alternative designs [27], thermal enhancement methods 
43 [28], daily performance [29] and working fluid investigation [30] of PTC also have

44 been carried out among the available literatures. While the simulation and modeling as

45 well as the performance analysis of the double-effect absorption system driven by PTC

46 require more research [31]. The superiorities of double-effect absorption chiller over

47 single-effect absorption chiller [32,33] and PTC over other thermal collectors [34] have

48 been demonstrated, respectively. The energy saving capability of integrating PTC with

49 double-effect absorption chiller has also been pointed out based on computer-code

50 model compared with several SHC systems for different climates [35]. A parametric

51 optimization of a small-scale SHC absorption prototype is presented [36] and the results

52 show that a properly designed system can potentially supply $39 \%$ of the cooling and

$5320 \%$ of the heating demand of the building. In general, many of the studies and research

54 papers focus on the performances of PTC-powered double-effect absorption system for

55 space cooling. The studies prove that $50 \%$ of the cooling load could be covered [37],

$56 \quad 69.47 \%$ of the solar energy utilization efficiency could be achieved [38] and $65 \%$ of the

57 annual operating costs could be reduced [39]. The contribution to $\mathrm{CO}_{2}$ emission

58 reduction of solar-assisted double-effect chillers is also pointed out compared to

59 conventional cooling system [40]. The comparison of different working pairs for

60 double-effect absorption chiller powered by PTC is investigated to enhance the

61 advantages of solar cooling system [41]. Analogously, despite some operating

62 behaviors of the SHC systems are taken into account [42], many of which have not

63 considered the annual operation by supplying both cooling and heating demand of 
64 buildings by solar thermal energy [31]. And to supplement this part of the research

65 could exploit the advantage of solar energy from annual dimension. Due to the varying

66 compatibility between solar source supply and load demand during heating and cooling

67 period, reasonable system form and operation mode therefore need to be considered.

68 The corresponding modeling simulation methods for annual system performance

69 analysis also need to be determined and improved.

70 To access the performance prediction of the SHC system over long periods of time,

71 simulation method based on equation solver is quite extensively used [43]. Therefore,

72 mathematical models are required. Some mathematical modeling of the PTC $[44,45]$

73 and absorption chiller [46] are developed respectively for applicability illustration.

74 Nevertheless, considering the performance interactions of the PTC and the absorption

75 chiller in practical, the annual system performance assessment and energy consumption

76 analysis need overall consideration. Therefore, integrated heat transfer models of the

77 whole system need to be considered for accurate prediction of the system performance.

78 Then, on the basis of the models, simulations for energetic, economic and

79 environmental performances of the SHC system can be carried out.

80 This paper presented a solar-assisted heating and cooling system which consisted

81 of PTC, double-effect $\mathrm{H}_{2} \mathrm{O} / \mathrm{LiBr}$ absorption chiller and plate heat exchanger (PHE).

82 Firstly, the SHC system was described in detail. The operational modes during the

83 cooling period and heating period were proposed. The working process of the

84 absorption chiller and the heat transfer mechanism of the PTC were analyzed. Secondly, 

the heat transfer models of the whole system including the PTC, the double-effect absorption chiller and the PHE were established in order to analyze the performance of the system. The proposed SHC system was designed and applied on an office building in Tianjin (China). Several field tests were carried out and the models were validated. Thirdly, the energetic, economic and environmental (3E) assessment method were introduced respectively. A building model in the prototype of the office building was developed. Finally, the simulation study was illustrated on the basis of the proposed mathematical models. The annual performances as well as energetic, economic and environmental (3E) assessments of the proposed SHC system were investigated compared with conventional gas-driven absorption heating and cooling (GHC) system.

The energy saving potential, economic viability and $\mathrm{CO}_{2}$ emission reduction effect were demonstrated.

\section{System description}

The major apparatuses of the SHC system are PTC, double-effect $\mathrm{H}_{2} \mathrm{O} / \mathrm{LiBr}$ absorption chiller and PHE. The SHC system can be divided into solar collector loop and load loop. The solar collector loop mainly consists of PTC which generates and supplies thermal energy to the absorption chiller for cooling or provides heating via PHE. The load loop comprises the double-effect absorption chiller loop and the PHE loop, which cover the building loads with the circuits of chilled water and hot water through the evaporator and the PHE respectively. The gas burner equipped in high pressure generator is used as a backup heater in case of solar energy shortage. The 


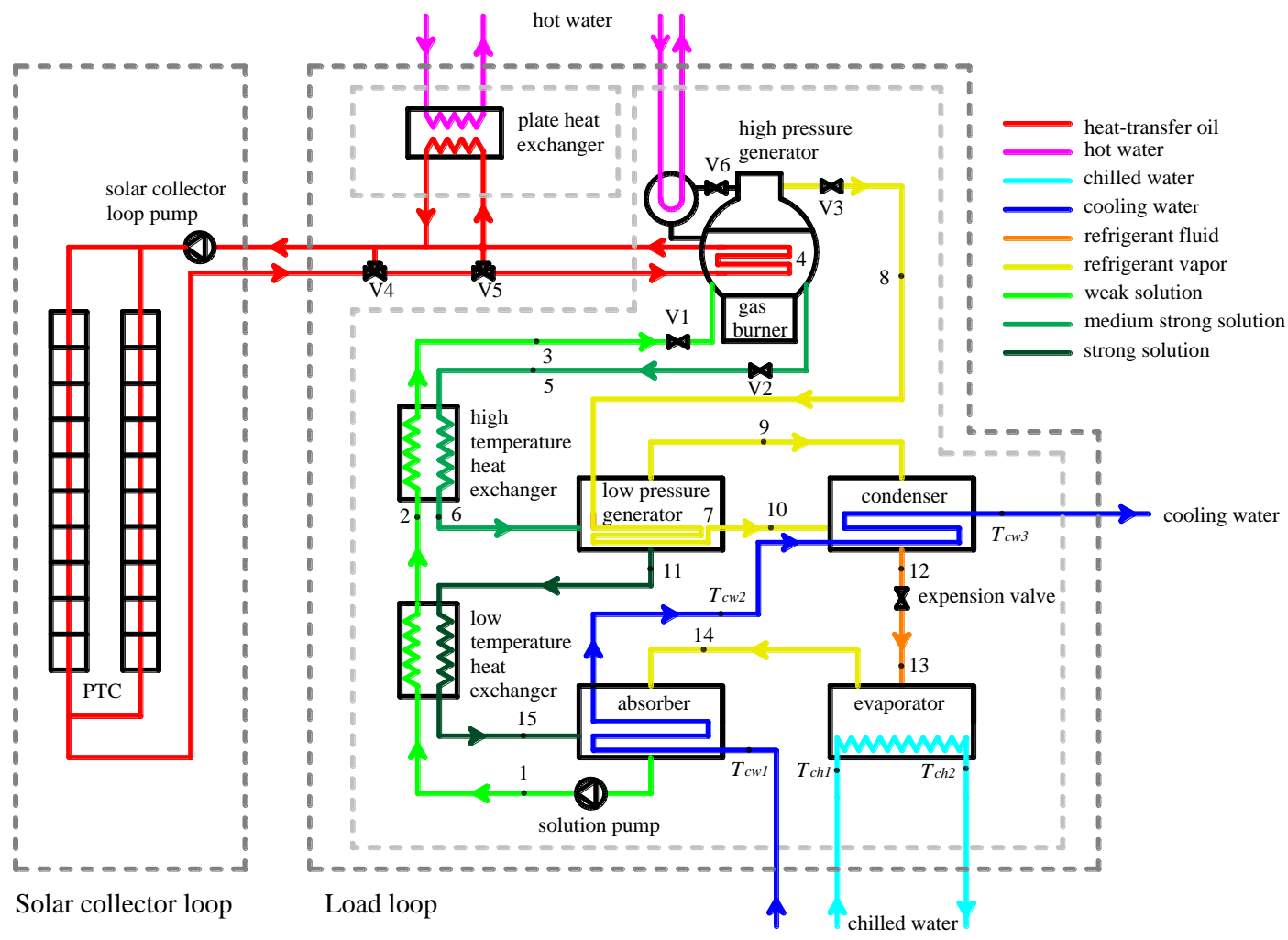

Fig. 1 Schematic diagram of the SHC system

110 is closed. The heat-transfer oil in PTC can be heated to $100^{\circ} \mathrm{C} \sim 250^{\circ} \mathrm{C}$. With the high

111 pressure generator branch opened by three-way valve V5, the thermal energy generated

112 by PTC can be supplied to the absorption chiller, thus refrigerant vapor could be boiled

113 off from weak solution. During the early period of system operation, the heat-transfer

114 oil is circulated in the collectors and heated by solar radiation with valve V4 closed.

115 The high pressure generator branch will be opened after the temperature of heat-transfer

116 oil meet the absorption chiller driven requirement. Under the priority of using solar

117 power, the double-effect refrigeration system can be powered by solar thermal and gas 
118 fired independently or simultaneously, depending on the intensity of the solar radiation.

119 During the heating period, valve V1, valve V2, valve V3 are closed. The heat-

120 transfer oil in PTC is heated to low temperature $\left(<100^{\circ} \mathrm{C}\right)$. The thermal energy derived

121 by PTC is directly used for heating purpose coupled with PHE. With the branch of PHE

122 opened by three-way valve V5, hot water can be supplied. Analogously, if the harvested

123 solar energy is not adequate for building demand, the gas burner installed in generator

124 will be activated. The heat-transfer oil is preheated in the collectors in the same way as

125 cooling condition.

$126 \quad 2.1$ The PTC

127 The PTC consists of parabolic trough shaped reflector, surface treated metallic

128 receiver tube, evacuated glass envelope, support structure and tracking mechanism. The

129 reflector concentrates direct solar radiation onto the receiver located at its focal line and

130 heats the transfer fluid in the tube. Fig. 2 illustrates the heat transfer model in a cross

131 section of the PTC.

132

133

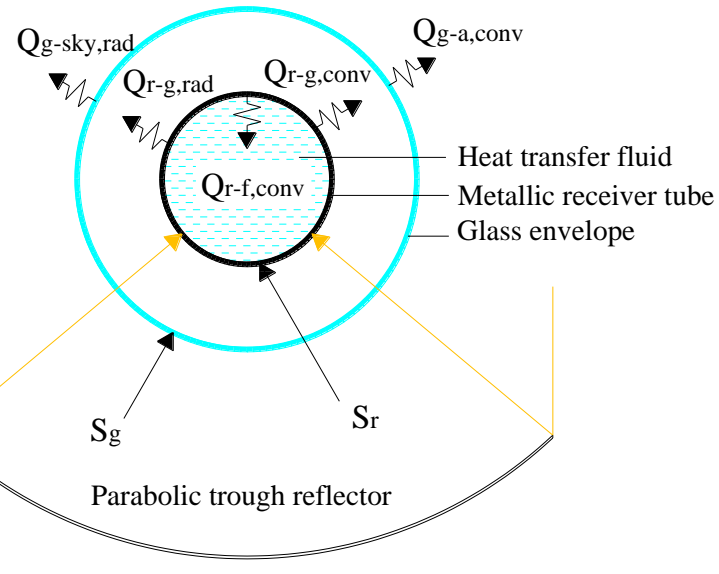

Fig. 2 Heat transfer model in a cross section of the PTC 
135 radiation is reflected by the parabolic trough shaped mirrors and concentrated at heat

136 collector element. A small amount of the radiation is absorbed by the glass envelope $S_{\mathrm{g}}$

137 and the remaining is transmitted and absorbed by the receiver tube $S_{\mathrm{r}}$. A part of the

138 absorption energy is transferred to the heat transfer fluid by forced convection $Q_{\text {r-f,conv }}$

139 and the other part is returned to the glass envelope by natural convention $Q_{\text {r-g,conv }}$ and

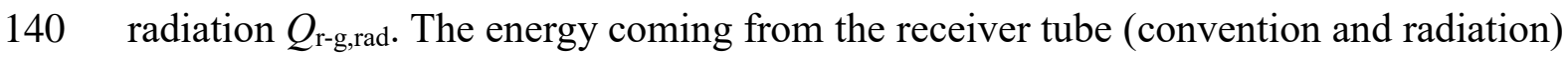

141 pass through the glass envelope and along with the absorbed energy by the glass

142 envelope, is lost to the environment by convention $Q_{\mathrm{g}-\mathrm{a}, \mathrm{conv}}$ and to the sky by radiation

$143 Q_{\text {g-sky,rad. }}$

\section{$144 \quad 2.2$ The absorption chiller}

145 The double-effect absorption chiller consists of seven main heat exchangers:

146 evaporator (EVA), absorber (ABS), condenser (CON), low pressure generator (LPG),

147 high pressure generator (HPG), low temperature heat exchanger (LEX) and high

148 temperature heat exchanger (HEX).

149 The working process of the chiller is as follows: the weak solution (state 1) pumps

150 through the LEX (state 2) and HEX (state 3) successively, and then is heated in the HPG

151 (state 4), turning into the medium strong solution (state 5) and refrigerant vapor (state

152 8). The thermal energy is provided by either the PTC or the natural gas burner. The

153 medium strong solution passes through the HEX (state 6), gets heated in the LPG (state

154 7) by the refrigerant vapor extracted from the HPG, and turns into strong solution (state 
155 11) and refrigerant vapor (state 9). The strong solution goes through the LEX (state 15)

156 and flows into the ABS. The generated refrigerant vapor (state 9 and state 10) enters

157 into the CON together and is cooled into liquid (state 12). The liquid refrigerant via the

158 expansion valve (state 13) goes into the EVA, becomes low pressure vapor (state 14),

159 enters into the ABS and is absorbed by the strong solution. The main state points from

1601 to 15 are represented in Fig. 1.

161 3. Model development

162 The integrated heat transfer models of the whole system including the PTC, the

163 double-effect absorption chiller and the PHE are established in Section 3.1 to Section

164 3.3. And the validations of the models are presented in Section 3.4.

$165 \quad 3.1$ PTC model

166 The mathematical model of the PTC consists of the energy conservation equations

167 of glass envelope, metallic receiver tube and heat transfer fluid. For simplicity, the

168 following assumptions are made $[47,48]$ :

169 - The heat transfer process is steady.

170 The heat flux around the circumference of the receiver tube and glass envelope is

$171 \quad$ uniform.

172 - The glass envelope is opaque to infrared radiation.

173 Only direct solar radiation is considered.

174 Heat loss through the supports is neglected.

175 Multiple reflections between receiver tube and glass envelope are neglected. 
176

178

179 calculated by:

$$
S_{\mathrm{g}}=\eta_{1} \eta_{2} \eta_{3} \eta_{4} \eta_{5} \eta_{6} \rho_{c} \cdot \eta_{I A M} \cdot \eta_{\text {end }} \cdot \alpha_{\mathrm{g}} \cdot W_{\mathrm{c}} \cdot l_{\mathrm{c}} \cdot I
$$

180 where $\eta_{1} \sim \eta_{6}$ are intercept factors accounted for the macroscopic imperfections

$181[49,50] ; \eta_{I A M}$ is incidence angle modifier which quantifies the optical losses [49,51];

$182 \eta_{\text {end }}$ is the geometrical end losses caused by the off-normal incidence angle [52]. The

183 incidence angle $(\theta)$ is a function of tracking mode and orientation of the PTC [53].

184 The convection heat transfer between glass envelope and receiver tube $Q_{\mathrm{rg}, \mathrm{g} \text { conv }}$ is

185 determined by:

$$
Q_{\mathrm{r}-\mathrm{g}, \mathrm{conv}}=\pi d_{\mathrm{rex}} l_{\mathrm{c}} h_{\mathrm{r}-\mathrm{g}}\left(T_{\mathrm{r}}-T_{\mathrm{g}}\right)
$$

186 in which the convective heat transfer coefficient $h_{\mathrm{r}-\mathrm{g}}$ is referred from Ref. [44],

187 considering the vacuum treatment.

188 The radiation heat transfer between glass envelope and receiver tube $Q_{\text {rgrad }}$ can

189 be obtained by:

$$
Q_{\mathrm{r}-\mathrm{g}, \mathrm{rad}}=\frac{\sigma\left(T_{\mathrm{r}}^{4}-T_{\mathrm{g}}^{4}\right)}{\left(1-\varepsilon_{\mathrm{g}}\right) /\left(\pi d_{\mathrm{g}, \mathrm{in}} l_{\mathrm{c}} \varepsilon_{\mathrm{g}}\right)+1 /\left(\pi d_{\mathrm{r}, \mathrm{ex}} l_{\mathrm{c}}\right)+\left(1-\varepsilon_{\mathrm{r}}\right) /\left(\pi d_{\mathrm{r}, \mathrm{ex}} l_{\mathrm{c}} \varepsilon_{\mathrm{r}}\right)}
$$

190 The convection heat transfer between glass tube and ambient air $Q_{\text {g-a,conv }}$ is given 191 as: 


$$
Q_{\mathrm{g}-\mathrm{a}, \mathrm{conv}}=\pi d_{\mathrm{g}, \mathrm{ex} \mathrm{c}} l_{\mathrm{g}-\mathrm{a}-\mathrm{g}}\left(T_{\mathrm{g}}-T_{\mathrm{a}}\right)
$$

192 where the calculation of the $h_{g-a}$ depends on the regime of convective heat transfer and 193 is referred from Ref. [54,55].

194 The radiation heat transfer between glass envelope and sky $Q_{\text {g-sky,ad }}$ can be 195 calculated as:

$$
Q_{\mathrm{g}-\mathrm{s}, \mathrm{rad}}=\sigma \pi d_{\mathrm{g}, \mathrm{ex}} l_{\mathrm{c}} \varepsilon_{\mathrm{g}}\left(T_{\mathrm{g}}^{4}-T_{\mathrm{sky}}{ }^{4}\right)
$$

196 where the sky temperature $T_{\text {sky }}(\mathrm{K})$ is given as:

$$
T_{\text {sky }}=0.0552 T_{\mathrm{a}}^{1.5}
$$

197

198

201 can be obtained by:

$$
Q_{\mathrm{rf}, \mathrm{conv}}=\pi d_{\mathrm{r}, \mathrm{in}} l_{\mathrm{c}} h_{\mathrm{rff}}\left(T_{\mathrm{r}}-T_{\mathrm{f}}\right)
$$

202 in which the $h_{\mathrm{r}-\mathrm{g}}$ can be calculated with Ref. [56,57], considering the transitional or 203 turbulent condition of the heat transfer fluid.

The total solar irradiation absorption of the receiver tube $S_{\mathrm{r}}$ can be calculated as:

$$
S_{\mathrm{r}}=\eta_{1} \eta_{2} \eta_{3} \eta_{4} \eta_{5} \eta_{6} \rho_{c} \cdot \eta_{I A M} \cdot \eta_{\text {end }} \cdot \tau_{\mathrm{g}} \cdot \alpha_{\mathrm{r}} \cdot W_{\mathrm{c}} \cdot l_{\mathrm{c}} \cdot I
$$

The convection heat transfer between receiver tube and heat transfer fluid $Q_{\mathrm{rf}, \mathrm{conv}}$

\author{
thentent condition of the heat transfer fluid.
}

\section{(3) Heat transfer fluid}

The energy conservation equation of heat transfer fluid is expressed as follows: 


$$
v_{\mathrm{f}} c_{p, \mathrm{f}} u_{\mathrm{f}} \pi \frac{d_{\mathrm{r}, \mathrm{in}}^{2}}{4}\left(T_{\mathrm{f}, \mathrm{int}}-T_{\mathrm{f}, \mathrm{out}}\right)+Q_{\mathrm{r}-\mathrm{f}, \mathrm{conv}}=0
$$

206

207 211 heat exchangers (EVA, ABS, CON, LPG, HPG, LEX and HEX). The correlations 212 between the working medium flow rates are also given in this section. Before describing 213 the mathematical equations, the main assumptions are taken into account as follows $214 \quad[34,46,58]:$

\section{(4)Efficiency}

The collector efficiency of the PTC can be calculated by [47]:

$$
\xi_{\mathrm{c}}=\frac{Q_{\mathrm{c}}}{W_{\mathrm{c}} \cdot l_{\mathrm{c}} \cdot I}=\frac{v_{\mathrm{f}} c_{p, \mathrm{f}} u_{\mathrm{f}} \pi d_{\mathrm{r}, \mathrm{in}}^{2}\left(T_{\mathrm{f}, \text { int }}-T_{\mathrm{f}, \text { out }}\right)}{4 W_{\mathrm{c}} \cdot l_{\mathrm{c}} \cdot I}
$$

\subsection{Double-effect absorption chiller model}

The mathematical model of the absorption chiller consists of mass conservation equations, energy conservation equations and heat transfer equations of the seven main

- The heat and mass transfer process is under steady state.

- The pressure of CON and LPG are identical.

- The solutions leaving ABS, HPG, and LPG are saturated.

- The refrigerants leaving the CON and the EVA are saturated.

- Heat loss to the environment is neglected.

- The pressure drops of the pipes and vessels are neglected and the solution pump energy is neglected.

\section{(1) Mass conservation equations}

Based on the mass balance of each component, the mass conservation equations 
224 are expressed as follows:

$$
\begin{aligned}
& a x_{1}=(a-1) x_{\mathrm{h}} \\
& a x_{1}=(a-y) x_{\mathrm{m}}
\end{aligned}
$$

equations are as follows:

$$
\begin{gathered}
Q_{i, 1}=-Q_{i, 2} \\
Q_{i, 1}=(G H)_{i, \mathrm{LiBr}, \text { int }}+(D H)_{i, \mathrm{re}, \text { int }}-(G H)_{i, \mathrm{LiBr}, \mathrm{out}}-(D H)_{i, \mathrm{re}, \mathrm{out}} \\
Q_{i, 2}=c_{p, i} G_{i}\left(T_{i, \mathrm{int}}-T_{i, \text { out }}\right)
\end{gathered}
$$

228 where $i$ could be $0, \mathrm{~A}, \mathrm{k}, \mathrm{lpg}$.

229 For the HPG, $Q_{\mathrm{hpg}, 1}$ is calculated with Eq. (16) $(i=\mathrm{hpg})$, while $Q_{\mathrm{hpg}, 2}$ is obtained 230 by Eq. (18).

$$
Q_{\mathrm{hpg}, 2}=c_{p, \mathrm{f}} G_{\mathrm{f}}\left(T_{\mathrm{f}, \mathrm{int}}-T_{\mathrm{f}, \mathrm{out}}\right)+\psi_{b} Q_{\mathrm{NG}}
$$

231 where $\psi_{b}$ is burner combustion ratio (\%).

232 For the LEX and HEX, the energy conservation equations are:

$$
\begin{gathered}
Q_{i, 1}=-Q_{i, 2} \\
Q_{i, 1}=(G H)_{i, 1, \text { int }}-(G H)_{i, 1, \text { out }} \\
Q_{i, 2}=(G H)_{i, j, \text { int }}-(G H)_{i, j, \text { out }}
\end{gathered}
$$

233 while $i=\mathrm{lex}, j=\mathrm{h} ; i=\mathrm{hex}, j=\mathrm{m}$.

\section{4 (3) Heat transfer equations}

235 The heat transfer equation is described as follows: 


$$
Q_{i, 3}=K_{i} F_{i} \frac{\Delta T_{i, 2}-\Delta T_{i, 1}}{\ln \frac{\Delta T_{i, 2}}{\Delta T_{i, 1}}}
$$

236 where $\Delta T_{i, 1}$ stands for the smaller temperature difference of the two heat exchange

237 fluid in component $i, \Delta T_{i, 2}$ stands for the larger one.

238 The total heat transfer coefficient $K_{i}$ of the component $i$ can be calculated as:

$$
\frac{1}{K_{i}}=\frac{1}{h_{i, \mathrm{ex}}}+\frac{1}{h_{i, \mathrm{in}}}\left(\frac{d_{i, \mathrm{ex}}}{d_{i, \mathrm{in}}}\right)+\frac{d_{i, \mathrm{ex}}}{2 \lambda_{i}} \ln \frac{d_{i, \mathrm{ex}}}{d_{i, \mathrm{in}}}
$$

239 in which $i$ could be $0, \mathrm{~A}, \mathrm{k}$, lex, hex, lpg, hpg. The calculations of the convective heat 240 transfer coefficients are referred from the Ref. [59].

\section{1 (4) Flow rate of working medium}

242 The flow rate of the working medium can be calculated as follows:

$$
\begin{gathered}
G_{1}=a D \\
G_{\mathrm{A}}=(a-1) D
\end{gathered}
$$

The refrigerant flow rate in the HPG and LPG can be calculated by Eqs. (26) and 244 (27).

$$
\begin{gathered}
G_{\mathrm{hpg}, \mathrm{re}}=y D \\
G_{\mathrm{lpg}, \mathrm{re}}=(1-y) D
\end{gathered}
$$

(5) Energy consumption index

The COP of the double-effect absorption chiller is defined as:

$$
C O P=\frac{Q_{0}}{Q_{\mathrm{hpg}}}
$$


249 equation are employed. And some assumptions are made as follows [60]:

250 - Heat loss to the surroundings is neglected.

251 - PHE operates under steady-state conditions.

252 - All the physical properties are constants.

253 - Phase of each fluid does not change in the flowing process.

254 - No heat exchange in the direction of flow.

255 - Distribution of flow through the channels of a pass is uniform.

256 The energy conservation equations are given by:

$$
\begin{gathered}
Q_{\mathrm{PHE}, 1}=-Q_{\mathrm{PHE}, 2} \\
Q_{\mathrm{PHE}, 1}=c_{p, \mathrm{f}} G_{\mathrm{f}}\left(T_{\mathrm{f}, \mathrm{PHE}, \mathrm{int}}-T_{\mathrm{f}, \mathrm{PHE}, \text { out }}\right)+\psi_{b} Q_{\mathrm{NG}} \\
Q_{\mathrm{PHE}, 2}=c_{p, \mathrm{hw}} G_{\mathrm{hw}}\left(T_{\mathrm{hw}, \mathrm{int}}-T_{\mathrm{hw}, \text { out }}\right)
\end{gathered}
$$

257 where the values of the $T_{\mathrm{f}, \mathrm{PHE}, \text { int }}$ and $T_{\mathrm{f}, \mathrm{PHE}, \mathrm{out}}$ in PHE are equal to the values of $T_{\mathrm{f}, \text { out }}$ 258 and $T_{\mathrm{f} \text {,int }}$ in PTC, respectively.

259 The heat transfer equation is the same as Eq. (22) $(i=\mathrm{PHE})$, in which the total heat 260 transfer coefficient $K$ can be obtained by:

$$
\frac{1}{K_{\mathrm{PHE}}}=\frac{1}{K_{\mathrm{f}}}+R_{\mathrm{f}}+\frac{\delta_{\mathrm{PHE}}}{\lambda_{\mathrm{PHE}}}+R_{\mathrm{hw}}+\frac{1}{K_{\mathrm{hw}}}
$$

261 where $R_{\mathrm{f}}$ and $R_{\mathrm{hw}}$ represent the fouling resistances on the plate surfaces corresponding to the heat-transfer oil side and the hot water side, respectively. Due to the complexity and mutual restraint between the temperature and concentration range of the solution, the models are solved using the subspace trust 
267 is shown in Fig. 3.

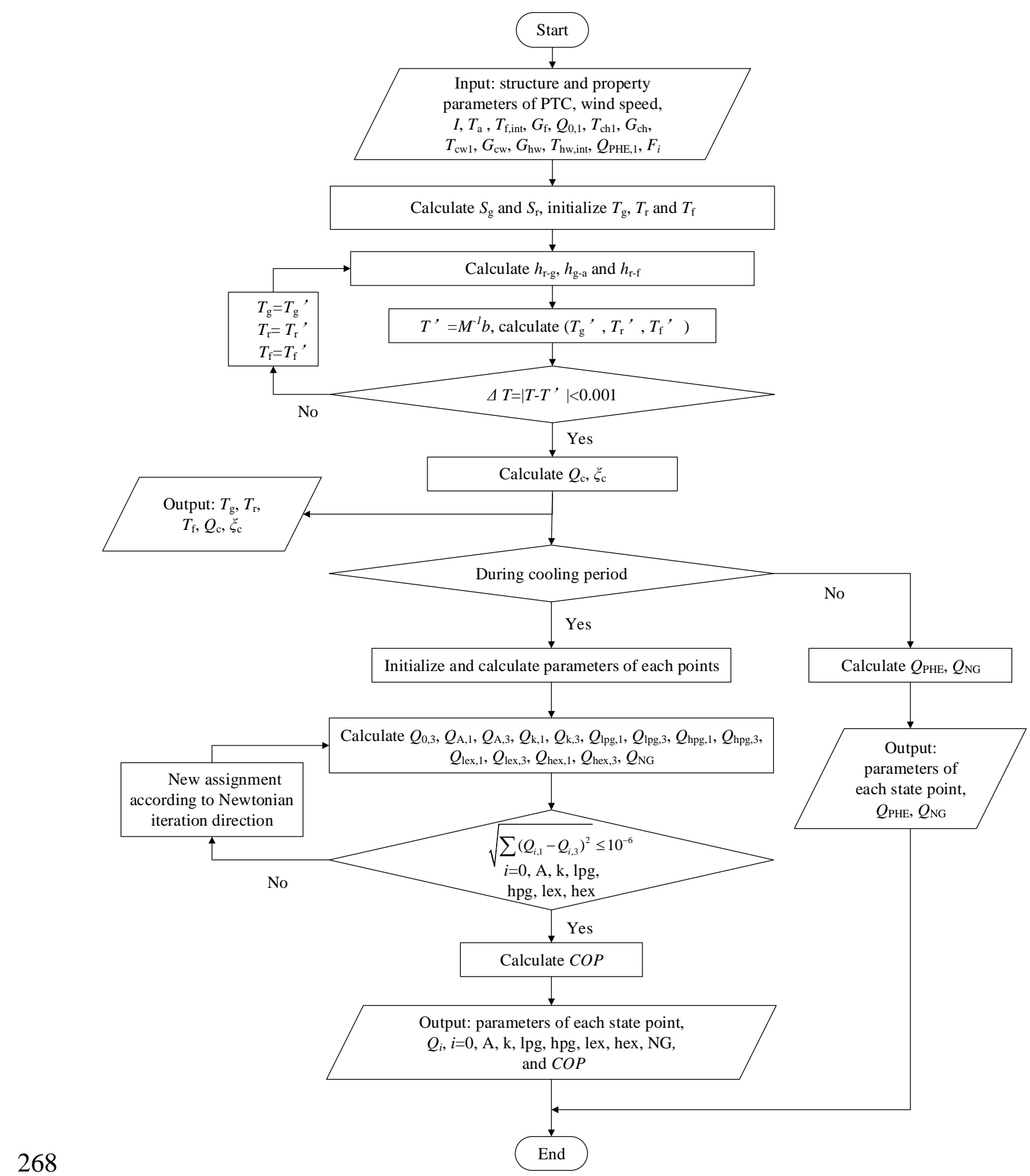

Fig. 3 Simulation flow chart of the proposed mathematical models 
In order to verify the accuracy and reliability of the proposed heat transfer models,

272 a PTC operated double-effect $\mathrm{H}_{2} \mathrm{O} / \mathrm{LiBr}$ absorption SHC system was designed and

273 applied on an office building in Tianjin (China). Several field tests were carried out.

274 The installed parabolic trough field comprised eight module groups assembled in

275 parallel and fixed on steel support structure in the east-west alignment adopted north-

276 south horizontal axis tracking method. The module groups measured $50 \mathrm{~m}$ long by $2.5 \mathrm{~m}$

277 width each, owing a total of $1000 \mathrm{~m}^{2}$ collecting area. Fig. 4 depicts the photograph of

278 the PTC. Synthetic oil was applied as heat transfer fluid in metallic receiver tubes. The

279 details of the material, optical and geometrical parameters of different components of

280 the PTC are provided in Table 1, and the specific parameters of the absorption chiller

$281 \quad$ are listed in Table 2.

282

283

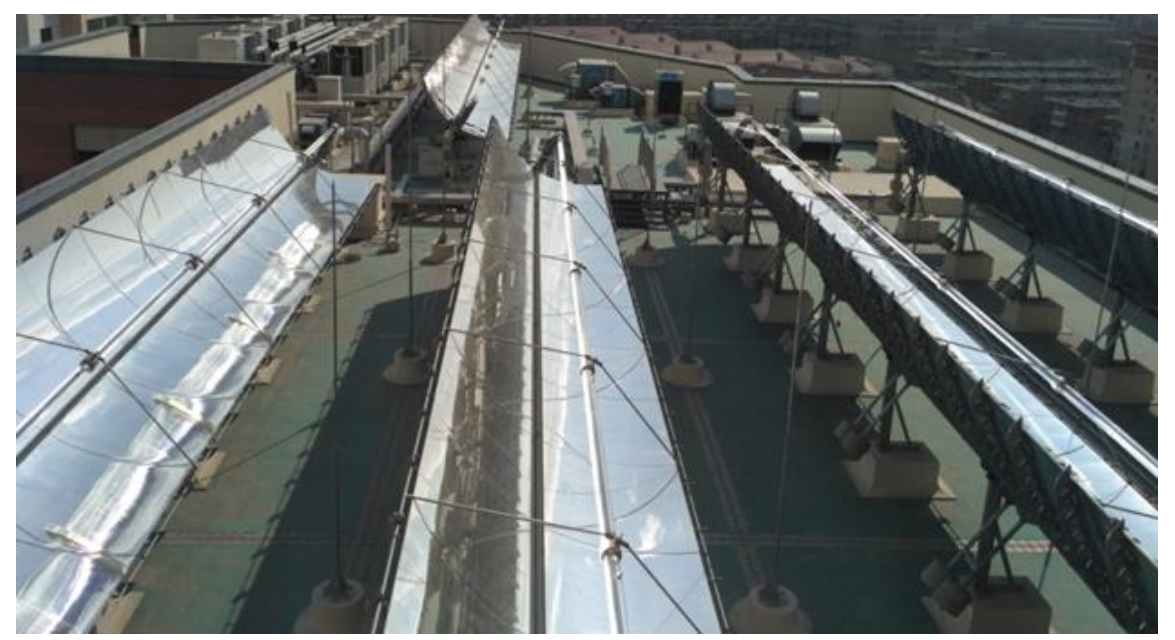

Fig. 4 Photograph of the PTC

284 Table 1

285 Parameters of the test PTC

\begin{tabular}{lll} 
Components & Parameters & Values \\
\hline Reflector & Material & Low-iron glass
\end{tabular}


$\begin{array}{ll}f_{\mathrm{c}}(\mathrm{m}) & 0.85 \\ \rho_{\mathrm{c}} & 0.90\end{array}$

Glass envelope

Material

Borosilicate glass

$d_{\mathrm{g}, \mathrm{in}} / d_{\mathrm{g}, \mathrm{ex}}(\mathrm{m})$

$0.096 / 0.102$

$\alpha_{\mathrm{g}}$

0.02

$\varepsilon_{\mathrm{g}}$

0.86

$\tau_{\mathrm{g}}$

0.90

Metallic receiver

Material

$d_{\mathrm{r}, \mathrm{in}} / d_{\mathrm{r}, \mathrm{ex}}(\mathrm{m})$

$0.038 / 0.042$

$\alpha_{\mathrm{r}}$

0.93

$\varepsilon_{\mathrm{r}}$

0.11

\section{Table 2}

287 Parameters of the test double-effect $\mathrm{H}_{2} \mathrm{O} / \mathrm{LiBr}$ absorption chiller

\begin{tabular}{ll} 
Parameters & Values \\
\hline Rated refrigerating capacity $(\mathrm{kW})$ & 1550 \\
Heat source temperature (K) & 433 \\
Heat exchange efficiency (\%) & 70 \\
$T_{\text {ch,int }} / T_{\text {ch,out }}(\mathrm{K})$ & $286 / 281$ \\
$T_{\text {cw,int }} / T_{\text {cw,out }}(\mathrm{K})$ & $303 / 308$ \\
$F_{\text {hpg }}\left(\mathrm{m}^{2}\right) / \Delta T_{\mathrm{hpg}}(\mathrm{K})$ & $66 / 10$ \\
$F_{\mathrm{lpg}}\left(\mathrm{m}^{2}\right) / \Delta T_{\mathrm{lpg}}(\mathrm{K})$ & $96 / 5$ \\
$F_{0}\left(\mathrm{~m}^{2}\right) / \Delta T_{0}(\mathrm{~K})$ & $225 / 3$
\end{tabular}



$F_{\mathrm{k}}\left(\mathrm{m}^{2}\right) / \Delta T_{\mathrm{k}}(\mathrm{K})$
$F_{\text {hex }}\left(\mathrm{m}^{2}\right)$
$F_{\text {lex }}\left(\mathrm{m}^{2}\right)$
26
$F_{\mathrm{A}}\left(\mathrm{m}^{2}\right)$
265

$289 \pm 2 \% \mathrm{~W} / \mathrm{m}^{2}$ accuracy) which measured the total solar irradiance and the scattered solar

290 irradiance, respectively. The solar irradiance was recorded in real time by a data

291 acquisition instrument with a sample interval of $1 \mathrm{~min}$. The outdoor air temperature was

292 measured using Temperature-Humidity automatic recorders (of $\pm 0.1^{\circ} \mathrm{C}$ and $\pm 1 \% \mathrm{RH}$

293 accuracy) with a sample interval of $1 \mathrm{~min}$. In order to reduce the test error, average value

294 was taken from three simultaneously recorded instruments. The outdoor wind speed

295 was measured using TSI anemometer (of $\pm 3 \% \mathrm{~m} / \mathrm{s}$ accuracy). Other operating

296 parameters were automatically collected and recorded by the system with sampling

297 interval of $1 \mathrm{~min}$. Specific information of the instruments are shown in Table 3.

$298 \quad$ Table 3

299 Technical parameters of the test devices

\begin{tabular}{lllll}
\hline Devices & Number & Accuracy & Full Scale & Sampling interval \\
\hline Solar radiometer & 2 & $\pm 2 \% \mathrm{~W} / \mathrm{m}^{2}$ & $0 \sim 2000 \mathrm{~W} / \mathrm{m}^{2}$ & - \\
Data acquisition instrument & 1 & - & - & $1 \mathrm{~min}$ \\
Temperature-Humidity & 3 & $\pm 0.1{ }^{\circ} \mathrm{C}$ & $-40 \sim 70{ }^{\circ} \mathrm{C}$ & \\
Automatic recorder & & & & $1 \mathrm{~min}$ \\
TSI anemometer & & $\pm 1 \% \mathrm{RH}$ & $0 \sim 100 \% \mathrm{RH}$ & \\
\hline
\end{tabular}


301 cooling conditions were selected. For heating conditions, the direct normal irradiance 302 varied from $500.8 \mathrm{~W} / \mathrm{m}^{2} \sim 710.2 \mathrm{~W} / \mathrm{m}^{2}$. The outdoor air temperature was in the range of $3038.9^{\circ} \mathrm{C} \sim 13.4^{\circ} \mathrm{C}$. The outdoor wind speed ranged from $0.7 \mathrm{~m} / \mathrm{s} \sim 1.9 \mathrm{~m} / \mathrm{s}$. For cooling 304 conditions, the direct normal irradiance varied from $650.6 \mathrm{~W} / \mathrm{m}^{2} \sim 807.4 \mathrm{~W} / \mathrm{m}^{2}$. The 305 outdoor air temperature was in the range of $31.6^{\circ} \mathrm{C} \sim 38.4^{\circ} \mathrm{C}$. The outdoor wind speed 306 ranged from $1.2 \mathrm{~m} / \mathrm{s} \sim 3.3 \mathrm{~m} / \mathrm{s}$. Several stable working conditions were also considered in 307 this paper for the double-effect absorption chiller model validation. The inlet 308 temperature of the cooling water varied from $30.3^{\circ} \mathrm{C} \sim 30.5^{\circ} \mathrm{C}$. The inlet temperature of 309 the chilled water was in the range of $12.7^{\circ} \mathrm{C} \sim 13.4^{\circ} \mathrm{C}$. To verify the models from an 310 overall dimension in system performance, the heat source for the absorption chiller was 311 provided by PTC, and therefore the performance interactions of the PTC and the 312 absorption chiller were considered and reflected. The heat source temperature ranged 313 from $138.2^{\circ} \mathrm{C} \sim 170^{\circ} \mathrm{C}$.

Fig.5 (a) and (b) show the comparison between the simulations and test 315 measurements on the outlet temperature of heat-transfer oil during cooling condition 316 and heating condition respectively. The simulated and measured results achieve good 317 agreement. The maximum deviation of heat-transfer oil outlet temperature is $0.55^{\circ} \mathrm{C}$ at 318 cooling condition and $0.87^{\circ} \mathrm{C}$ at heating condition. Fig.6 shows the simulated and 319 measured results of the PTC efficiency. The simulated efficiency is slightly higher than 320 the measured ones with a difference lower than 5.4\%. Considering the heat loss through 
321 the bracket and tube ends are ignored in the heat transfer models, the agreement can be

322 considered as reasonably accurate for analyzing and predicting PTC performance.

323 As it is highlighted in the Fig. 7, the COP in test varies from 1.05 to 1.38 . The

324 maximum deviation between simulated results and test measurements is 0.04 ,

325 accounted for $3.7 \%$ error. Fig. 8 shows the variation of COP under different heat source

326 temperature. With the increasing of the heat source temperature, the performance of the

327 absorption chiller improves. This is benefit from the increasing of generation

328 temperature, and the refrigerant evaporation therefore increased. The upward trend

329 becomes relatively slow after the heating source temperature raised above $152.5^{\circ} \mathrm{C}$.

330 This can be accounted by the limitation of the heat transfer area in generator. The

331 comparison results indicate that the proposed mathematical models are acceptable for

332 the performance analysis of the SHC system.

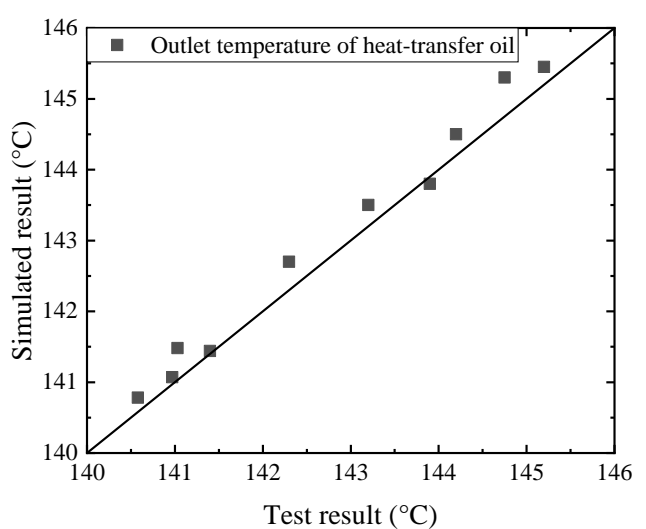

(a) Cooling condition

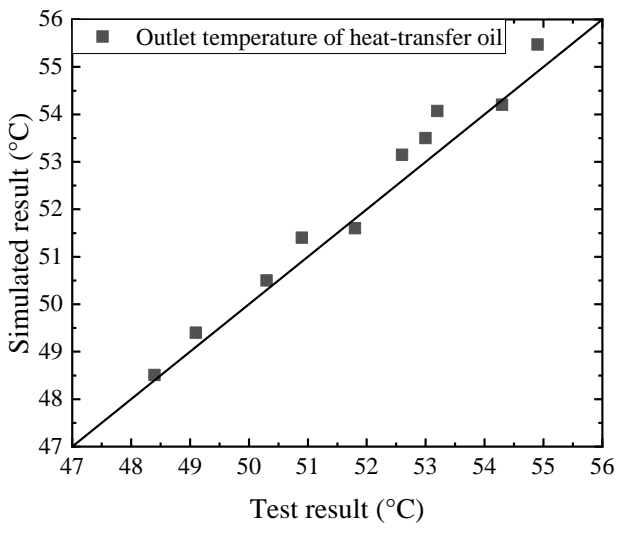

(b) Heating condition

Fig. 5 Comparison results of heat-transfer oil outlet temperature 


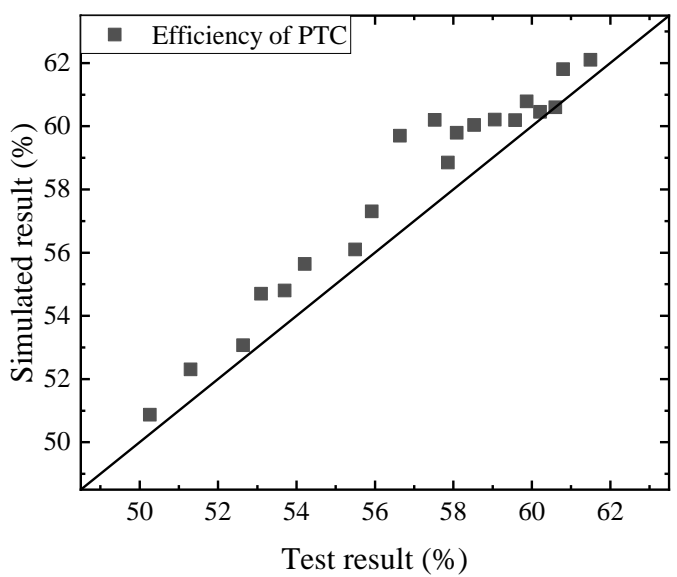

Fig. 6 Comparison results of PTC efficiency

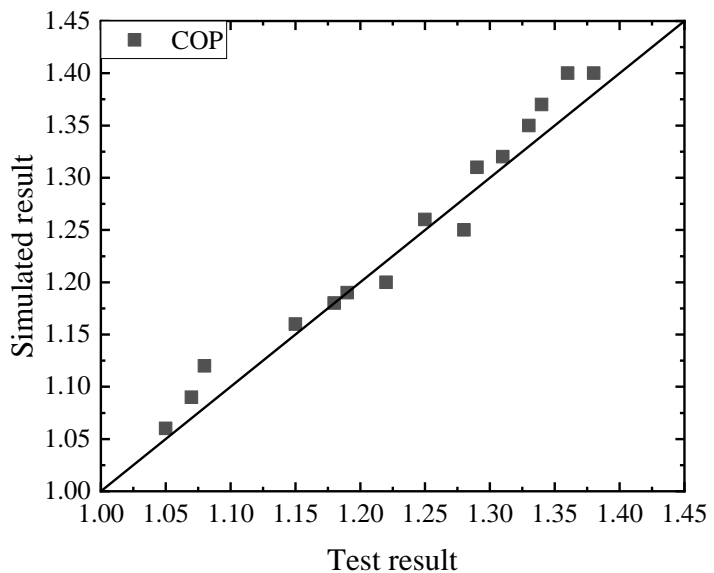

Fig. 7 Comparison results of COP

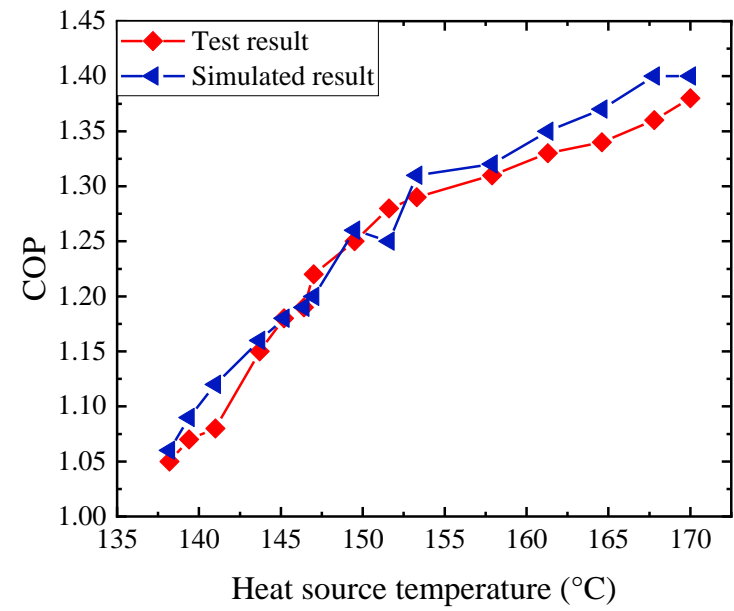

Fig. 8 Variation of COP under different heat source temperature 


\section{Methodologies of 3E analysis}

In this section, the energetic, economic and environmental (3E) assessment

344 methods are introduced respectively. In order to investigate the annual performance of

345 the SHC system, the conventional commonly used gas-driven absorption heating and

346 cooling system (GHC) is selected as the reference.

347

348

consumed by each configuration.

$$
\begin{aligned}
& P E C_{\mathrm{SHC}}=P E F_{\mathrm{E}} \cdot E_{\mathrm{E}, \mathrm{SHC}}+P E F_{\mathrm{NG}} \cdot E_{\mathrm{NG}, \mathrm{SHC}} \\
& P E C_{\mathrm{ref}}=P E F_{\mathrm{E}} \cdot E_{\mathrm{E}, \mathrm{ref}}+P E F_{\mathrm{NG}} \cdot E_{\mathrm{NG}, \mathrm{ref}}
\end{aligned}
$$

352 where $E_{\mathrm{E}}$ and $E_{\mathrm{NG}}$ are annual energy consumed of the electric equipment and gas

353 burner respectively; $P E F_{\mathrm{E}}$ and $P E F_{\mathrm{NG}}$ denote the primary energy factors, which are 354 adopted as 3.58 and 1.64 respectively in this paper [62].

Accordingly, the PES can be obtained as follows:

$$
P E S=P E C_{\text {ref }}-P E C_{\mathrm{SHC}}
$$

In this paper, primary energy ratio (PER) is also calculated by Eqs. (36) and (37)

357 to evaluate the system energy saving potential, which indicates how much usable energy

358 can be generated per primary energy input [63]. 


$$
\begin{aligned}
& P E R_{\mathrm{SHC}}=\frac{Q_{\mathrm{cap}}}{E_{\mathrm{NG}, \mathrm{SHC}} / \xi_{\mathrm{NG}}+E_{\mathrm{E}, \mathrm{SHC}} / \xi_{\mathrm{E}}} \\
& P E R_{\mathrm{ref}}=\frac{Q_{\mathrm{cap}}}{E_{\mathrm{NG}, \mathrm{ref}} / \xi_{\mathrm{NG}}+E_{\mathrm{E}, \mathrm{ref}} / \xi_{\mathrm{E}}}
\end{aligned}
$$

\subsection{Economic analysis}

The SHC technology is generally characterized by relatively high capital investment and low operational cost. The high initial cost, particularly the cost of the collectors, represents a major economic hurdle for these systems [64]. Therefore, it is necessary to take both capital and operating costs into account in an economic evaluation of the proposed system, in order to enable better long-term decision making. The payback period (PBP) is adopted as economic criteria in this paper to determine the financial performance on energy efficiency project. The PBP is defined as the length of time required for the cash inflows to recover its initial investment costs.

The additional capital investment costs of the SHC system can be compensated over time due to cumulative savings from operating and maintenance costs. Thus the PBP of the SHC system can be estimated from Eq. (38).

$$
P B P=\frac{C_{\mathrm{SHC}}-C_{\mathrm{ref}}}{A_{\mathrm{ref}}-A_{\mathrm{SHC}}}
$$

where $C$ and $A$ are initial cost and annual operating cost of the system respectively.

\subsection{Environmental analysis}

Due to the increasing environmental concerns, it is necessary to consider the environmental impacts while designing energy systems [65]. In the present study, the annual carbon dioxide emission (CDE) is estimated to identify the environmental effect, 
376 which can be formulated as [15]:

$$
C D E=C D E_{\mathrm{E}}+C D E_{\mathrm{NG}}
$$

377 in which

$$
\begin{gathered}
C D E_{\mathrm{E}}=E_{\mathrm{E}} \cdot E F_{\mathrm{E}} \\
C D E_{\mathrm{NG}}=E_{\mathrm{NG}} \cdot E F_{\mathrm{NG}}
\end{gathered}
$$

378 where $E F$ is $\mathrm{CO}_{2}$ emission factor.

\subsection{Cooling/heating load simulation}

In order to conduct the simulations for $3 \mathrm{E}$ assessments on the basis of the proposed mathematical models, the aforementioned office building in Section 3.4 is taken as a prototype and the three dimensional design of the building is developed which is shown in Fig. 9.

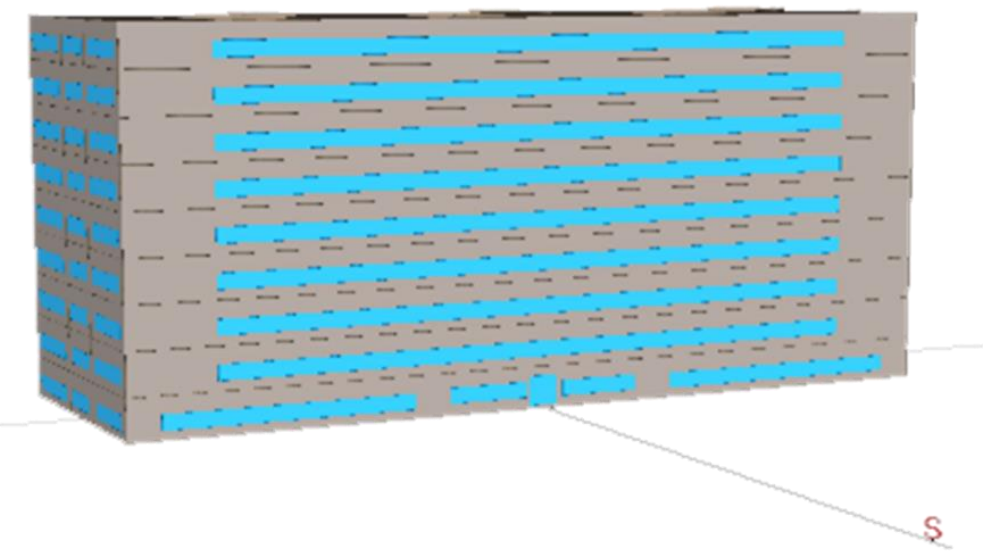

Fig. 9 Three dimensional model of the office building

The office building consists of 9 floors with total air-conditioning area of $18270 \mathrm{~m}^{2}$. The input weather parameters adopt the Chinese Standard Weather Data based on typical meteorological year in energy simulation software [66]. The hourly building loads during cooling period (date 15 Jun to 15 Sep) and heating period (date 15 Nov to 
391 peak cooling load and peak heating load are $1531.7 \mathrm{~kW}$ and $1258.2 \mathrm{~kW}$, respectively.

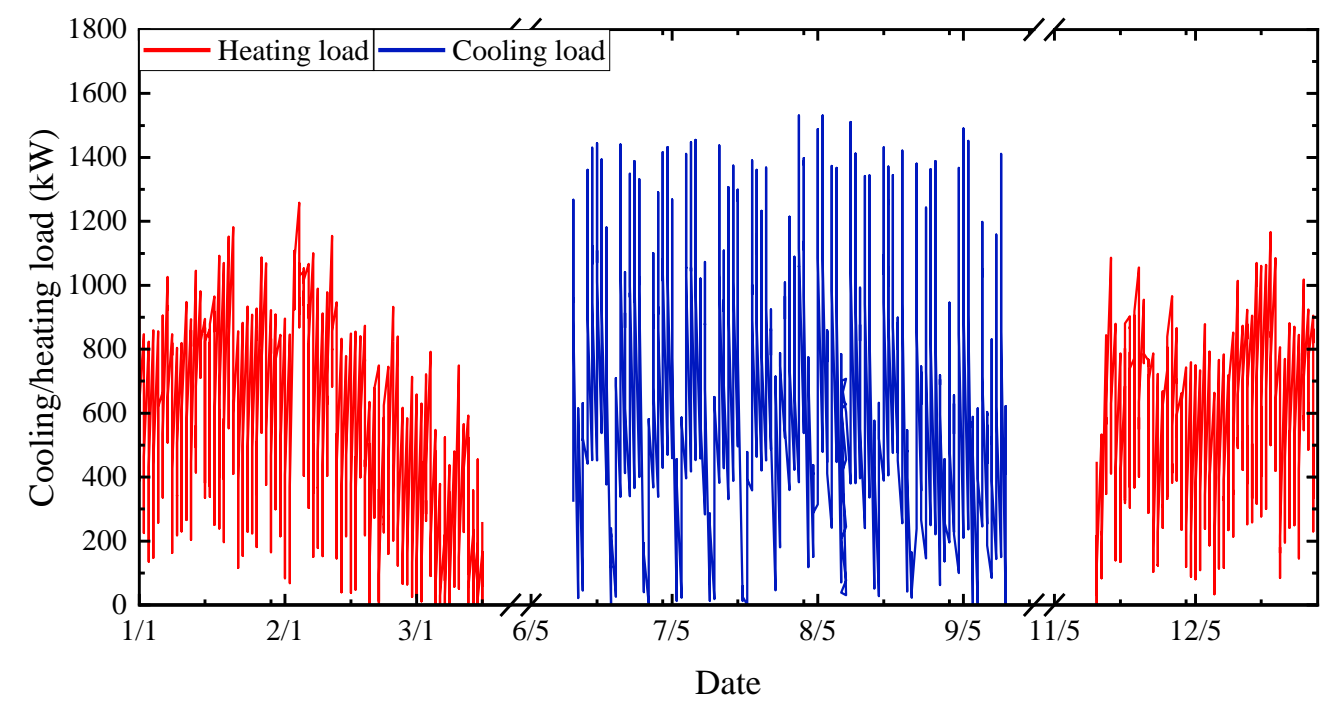

392 bulb temperature and high wind speed. The other is the similar peak normal direct solar radiation throughout the year. Besides, the solar heat collection ability during cooling

403 period is more stable than that during heating period, which provides an ideal heat 404 source for the double-effect absorption chiller. 


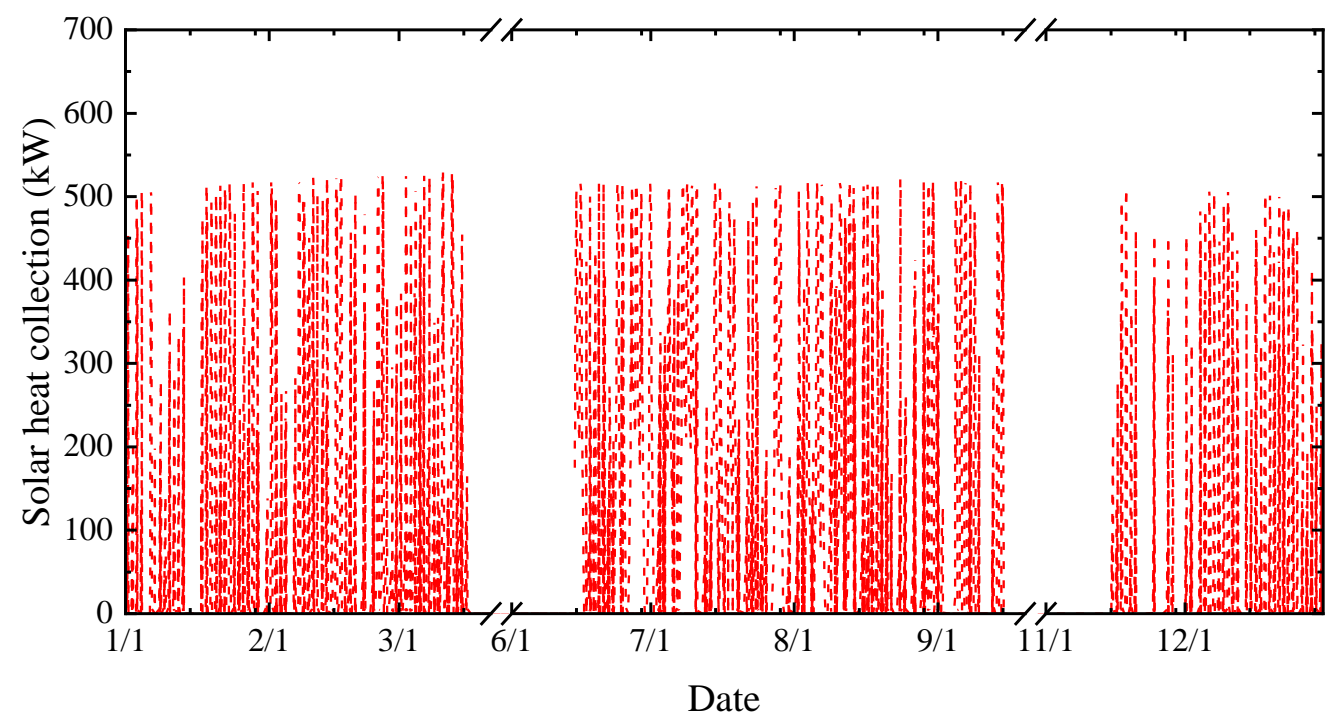

405

406

411 be more impressive in the areas with rich solar energy. By contrast, the conventional 412 gas-driven absorption heating and cooling system (GHC) is completely dependent on 413 natural gas. Therefore, benefited from the solar heat collection, certain advantages in 414 natural gas saving is found in the SHC system. The total annual natural gas consumption 415 of the SHC system and the GHC system is presented in Fig. 12. 


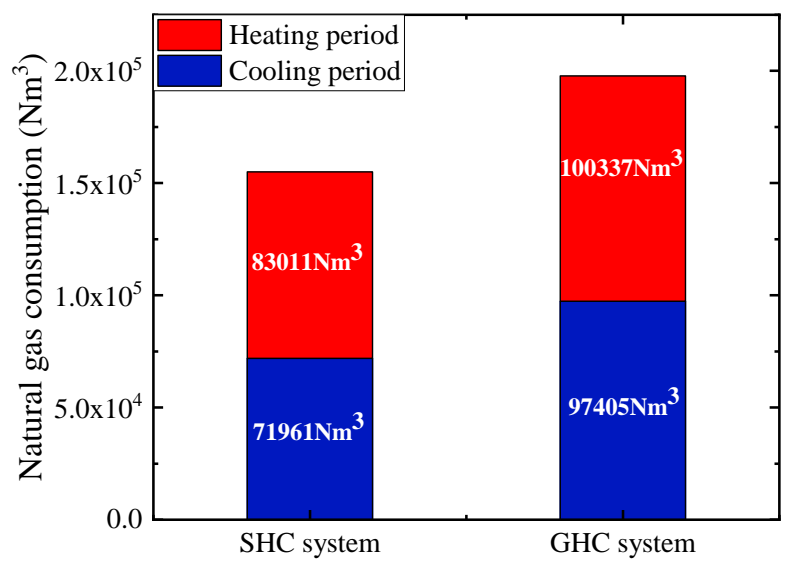

419 period and $83011 \mathrm{Nm}^{3}$ during heating period, with the total annual natural gas

420 consumption of $154972 \mathrm{Nm}^{3}$. For the GHC system, the natural gas consumption during

421 cooling period and heating period are $97405 \mathrm{Nm}^{3}$ and $100337 \mathrm{Nm}^{3}$ respectively, with the

422 total of $197742 \mathrm{Nm}^{3}$. Compared with the GHC system, the natural gas saving of the

423 SHC system is $25444 \mathrm{Nm}^{3}$ in cooling condition and $17326 \mathrm{Nm}^{3}$ in heating condition,

424 accounting for $35.4 \%$ and $20.9 \%$ of the gas consumption of the system in the 425 correspondingly period. Fig. 13 presents the hourly natural gas saving of the SHC 426 system. As a whole, the total annual natural gas saving of the SHC system is $42770 \mathrm{Nm}^{3}$, 427 accounting for $27.6 \%$ of the gas consumption of the system. 


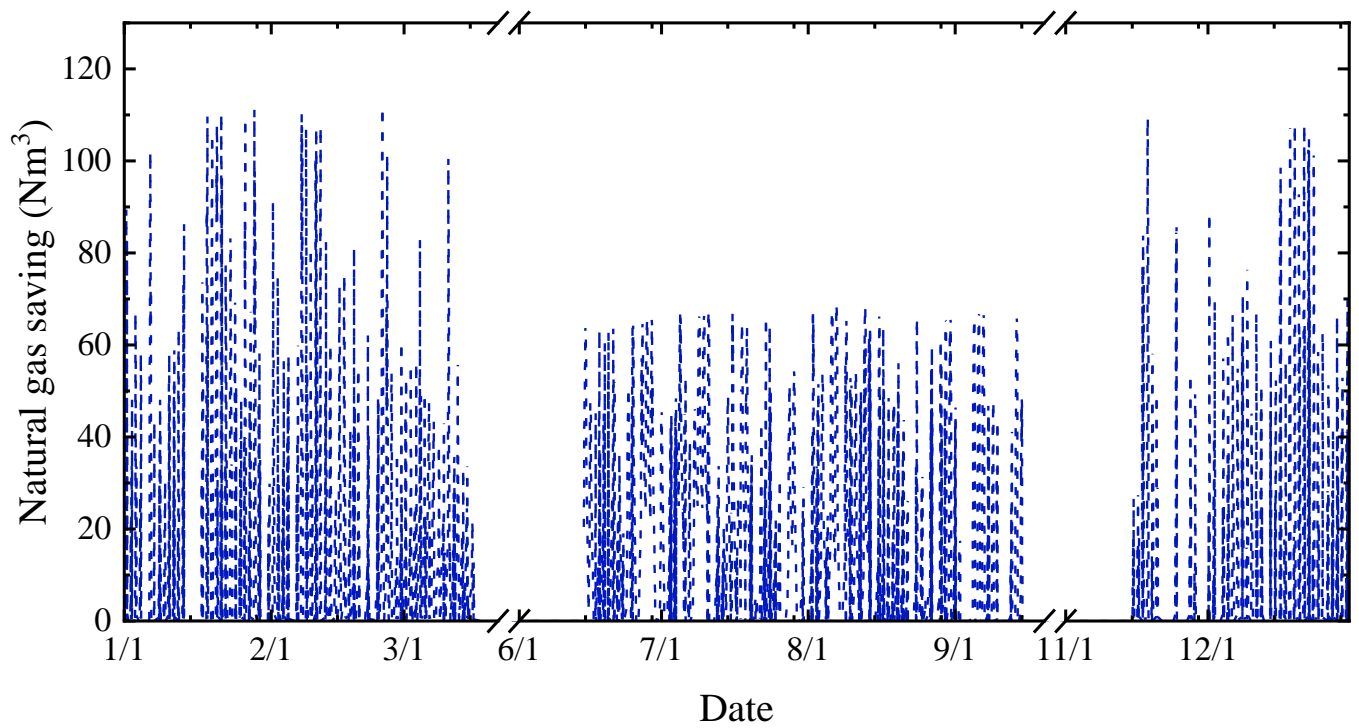

428

429

431 presented in Fig. 14 (a) and (b). Since there is a positive relationship between cooling

432 load and solar irradiance intensity, peak-shaving effect on natural gas consumption is

433 achieved under the SHC system in cooling condition, thus fully ensure the operational

434 reliability during the peak load period. More specifically, the peak consumption of

435 natural gas during cooling period of the $\mathrm{SHC}$ system is $156 \mathrm{Nm}^{3} / \mathrm{h}$, and the proportion

436 in excess of $100 \mathrm{Nm}^{3} / \mathrm{h}$ is $16.1 \%$, which is much lower than the $38.6 \%$ of the GHC

437 system. During the heating period, considering the (1) efficiency of plate heat

438 exchanger and gas burner are less than 1 in practical; (2) weak solar irradiance during

439 winter in this area; (3) inverse relationship between thermal load and solar irradiance

440 intensity, the unobvious effect of peak balance can be explained. 


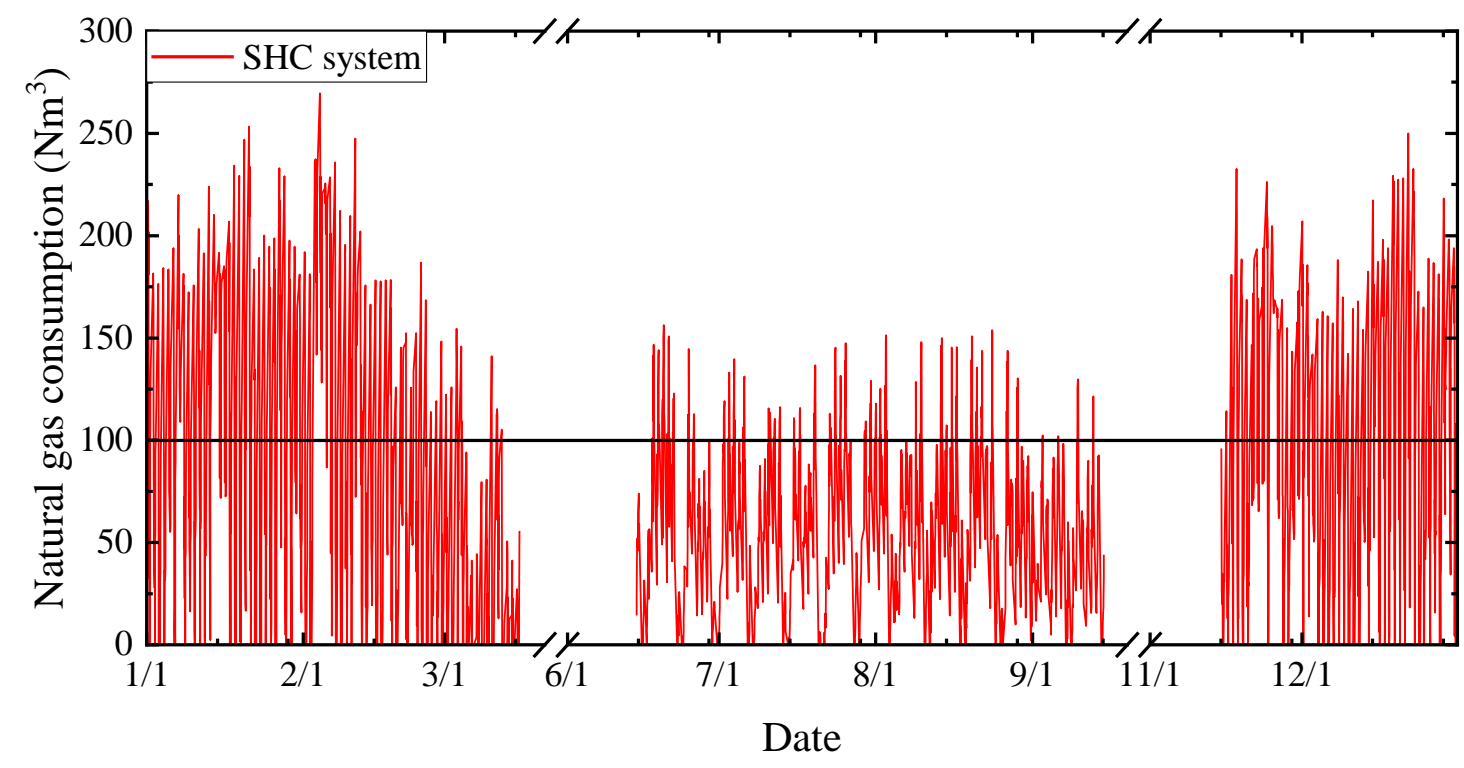

(a) Hourly natural gas consumption of SHC system

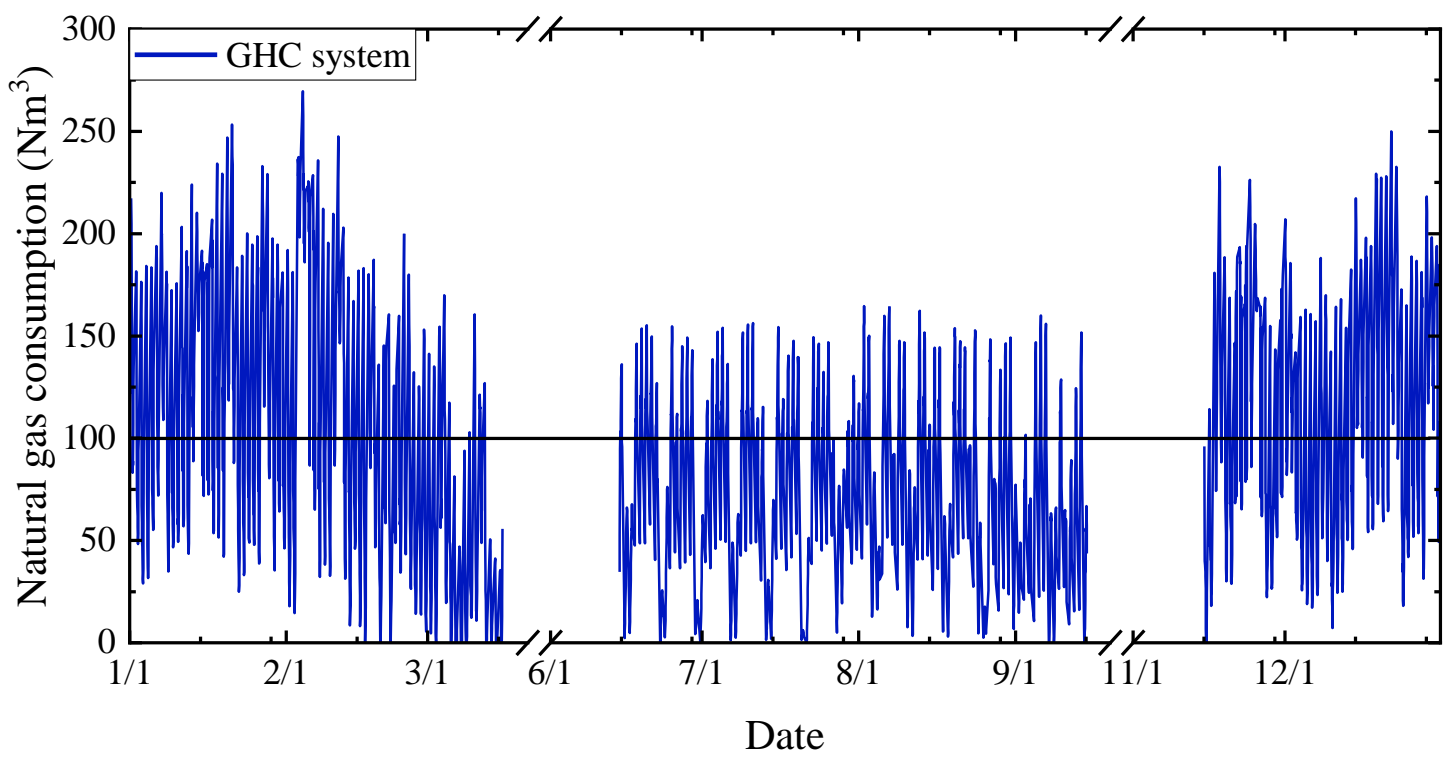

(b) Hourly natural gas consumption of GHC system

Except for the natural gas consumption, the electricity consumption is also calculated, which mainly dominates by chiller unit (both in the SHC system and the

448 GHC system) and the solar system related equipments (in the SHC system only). And 
449 the solar system related equipments include the solar collector loop pump and the 450 tracking system, etc. As shown in Fig. 15 (a), there is not too much difference in unit 451 power consumption between the two systems, with $14150 \mathrm{kWh}$ for SHC system and $45214670 \mathrm{kWh}$ for GHC system. Considering the variety of heating and cooling loads, the 453 intensity of the solar radiation as well as the COP of the absorption chiller, the difference 454 in electricity consumption of the unit during the heating and cooling period is obvious. 455 Fig. 15 (b) presents the extra electricity consumption of the solar system related 456 equipments in the SHC system, of which $12880 \mathrm{kWh}$ is during cooling period and $45711060 \mathrm{kWh}$ is during heating period, with the total of $23940 \mathrm{kWh}$. Since there is little 458 fluctuation of electricity consumption for this part, the basically similar amount of 459 electricity consumption during heating and cooling period is found.

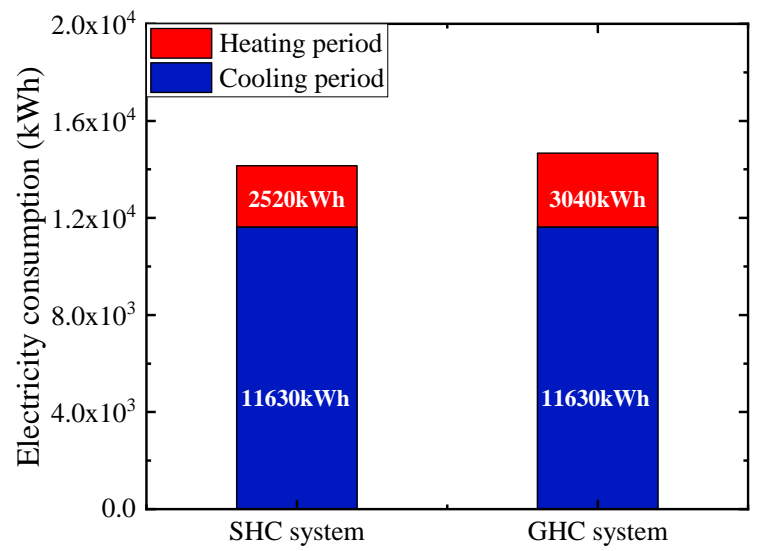

461

(a) Electricity consumption of the unit 

absorption chiller adopt $70 \%$, which means $70 \%$ of the total natural gas calorific value is consumed and used for the system. According to the calculation by Eqs. (33) to (35),

469 the annual PEC of the SHC system and GHC system are $1915 \mathrm{MWh} /$ year and 470

(b) Electricity consumption of solar system related equipments

Fig. 15 Total annual electricity consumption of the SHC system and GHC system

In this paper, the primary energy factors of electricity $\left(P E F_{\mathrm{E}}\right)$ and natural gas $\left(P E F_{\mathrm{NG}}\right)$ are 3.58 and 1.64 respectively, and the burner combustion ratio of the the annual PEC of the SHC system and GHC system are $1915 \mathrm{MWh} / \mathrm{year}$ and $2323 \mathrm{MWh} /$ year, respectively. Thus the PES of the SHC system is $408 \mathrm{MWh} / \mathrm{year}$, accounting for $21.3 \%$ of the total primary energy consumption, which shows obvious energy saving benefit.

The energy saving potential of the SHC system is also shown by the calculation of PER. The PER of the SHC system is 1.49 during the cooling period and 1.055 during the heating period, while the PER of the GHC are 1.177 and 0.911 respectively.

\subsection{Economic performance}

To carry out an economic analysis, various financial assumptions are made, as summarized in Table 4.

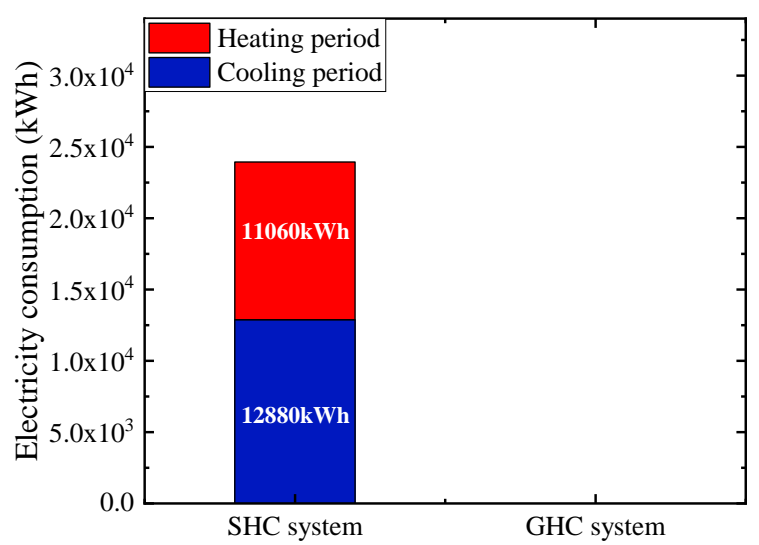




\section{Table 4}

Financial assumptions for economic calculation

\begin{tabular}{ll} 
Items & Values \\
\hline PTC & $1000 \mathrm{RMB} / \mathrm{m}^{2}$ \\
Intelligent control system & $50000 \mathrm{RMB} / \mathrm{suit}$ \\
Tracking system & $8000 \mathrm{RMB} / \mathrm{suit}$ \\
Solar loop pump & $4000 \mathrm{RMB} / \mathrm{suit}$ \\
Plate heat exchanger & $30000 \mathrm{RMB} / \mathrm{suit}$ \\
& \\
Natural gas & $2.66 \mathrm{RMB} / \mathrm{Nm}{ }^{3}$ \\
& \\
Electricity & $0.68 \mathrm{RMB} / \mathrm{kWh}$ \\
\hline
\end{tabular}

The extra initial cost of the SHC system dominates by the solar collecting related

482 configurations. The cost is 1176 thousand RMB according to the calculation. The 483 operating costs mainly include the natural gas cost and the electricity cost. After 484 calculation, $A_{\text {ref }}$ and $A_{\mathrm{SCH}}$ are 438 thousand $\mathrm{RMB}$ and 536 thousand RMB 485 respectively, which demonstrates the advantage of the SHC system in operating cost 486 reduction. The calculated PBP of the SHC system is 12 years. Since the cost of the PTC 487 collectors account for $85 \%$ of the total investment, with the unit price of the PTC (per 488 square meter) dropping by $50 \%$, the initial investment will drop by $42.5 \%$ to 676 489 thousand RMB, and the PBP will be reduced to 6.9 years. And according to the analysis 490 in Section 5.1, the additional capital investment cost of the SHC system will be 491 compensated over time due to cumulative savings from energy cost. Therefore, with the 492 decrease of the collector unit price and the increase of energy price, SHC system would 
be more economically attractive.

494

497

\subsection{Environmental performance}

According to the calculation, the annual CDE of the SHC system and GHC system are 223ton/year and 264ton/year, respectively. Thus the $\mathrm{CO}_{2}$ emission reduction of the $\mathrm{SCH}$ system is $42 \mathrm{ton} /$ year, accounting for $18.8 \%$ of the total $\mathrm{CO}_{2}$ emission, which shows considerable emission reduction effect.

\section{Conclusions}

In this paper, a comprehensive study on an integrated solar heating and cooling (SHC) system driven by double-effect $\mathrm{H}_{2} \mathrm{O} / \mathrm{LiBr}$ absorption chiller and parabolic trough collectors (PTC) was carried out. The operational modes during the cooling period and heating period were proposed. The heat transfer models of the whole system including the PTC, the double-effect absorption chiller and the plate heat exchanger (PHE) were developed and validated, according to the analysis of seven main heat exchangers of the absorption chiller and heat transfer mechanism of the PTC and PHE. To assess the performances of the system, simulations based on a building model were carried out. Annual performances as well as energetic, economic and environmental (3E) assessments of the SHC system were investigated compared with conventional gasdriven absorption heating and cooling (GHC) system. The following results have been conducted.

- The proposed mathematical models are validated against the field test results with good agreement. The maximum deviation of heat-transfer oil outlet temperature is 
$514 \quad 0.55^{\circ} \mathrm{C}$ at cooling condition and $0.87^{\circ} \mathrm{C}$ at heating condition. The simulated 515 efficiency is slightly higher than the measured ones with a difference lower than $5165.4 \%$. The maximum deviation of COP between simulated results and test 517 measurements is 0.04 , accounted for $3.7 \%$ error. The comparison results indicate 518 that the proposed mathematical models are acceptable for the performance analysis 519 of the SHC system.

520 - A basically $500 \mathrm{~kW}$ of peak solar heat collection during cooling and heating period 521 is illustrated. And the more stable heat collection ability during cooling period than 522 that during heating period could provide an ideal heat source for the double-effect $523 \quad$ absorption chiller to cover building loads.

524 - The SHC system is potential in peak-shaving on natural gas consumption. The peak 525 consumption of natural gas during cooling period is $156 \mathrm{Nm}^{3} / \mathrm{h}$, and the proportion 526 in excess of $100 \mathrm{Nm}^{3} / \mathrm{h}$ is $16.1 \%$, which is much lower than the $38.6 \%$ of the GHC $527 \quad$ system.

528 The SHC system has certain advantages in energy saving. The solar heat collection 529 accounts for $30.7 \%$ of the total heat requirement of the system during cooling 530 period and $23.2 \%$ during heating period. Compared with the GHC system, the 531 annual natural gas saving is $42770 \mathrm{Nm}^{3}$, accounting for $27.6 \%$ of the gas 532 consumption of the system. The primary energy saving (PES) of the SHC system 533 is $408 \mathrm{MWh} /$ year, accounting for $21.3 \%$ of the total primary energy consumption. 534 The primary energy ratio (PER) of the SHC system is 1.49 during the cooling 
535 period and 1.055 during the heating period, while the PER of the GHC are 1.177 536 and 0.911 respectively.

537 - The SHC system has potential optimistic economic viability. The payback period 538 (PBP) of the SHC system is 12 years and the cost of the PTC collector is found to 539 be the key parameter impacting the PBP which accounts for $85 \%$ of the total 540 investment. With the unit price of PTC (per square meter) dropping by $50 \%$, the 541 initial investment will drop by $42.5 \%$, and the PBP will be reduced to 6.9 years. 542 Therefore, with the unit price of collector decreasing and the energy price 543 increasing, SHC system would be more economically attractive.

544 - The SHC system shows considerable emission reduction effect. Obvious $\mathrm{CO}_{2}$ 545 emission reduction with 42ton/year is shown in $\mathrm{SCH}$ system, which accounts for $546 \quad 18.8 \%$ of the total $\mathrm{CO}_{2}$ emission. 
548 [1] R. Hitchin, C. Pout, D. Butler, Realisable 10-year reductions in European energy consumption for air conditioning, Energy Build. 86 (2015) 478-491. doi:10.1016/j.enbuild.2014.10.047.

550 [2] F.A. Boyaghchi, P. Heidarnejad, Thermoeconomic assessment and multi objective optimization Convers. Manag. 97 (2015) 224-234. doi:10.1016/j.enconman.2015.03.036.

[3] Z. Sayadi, N. Ben Thameur, M. Bourouis, A. Bellagi, Performance optimization of solar driven Manag. 74 (2013) 299-307. doi:10.1016/j.enconman.2013.05.029.

556 [4] A. Buonomano, F. Calise, A. Palombo, Solar heating and cooling systems by absorption and doi:10.1016/j.rser.2017.07.056.

[5] A. Aliane, S. Abboudi, C. Seladji, B. Guendouz, An illustrated review on solar absorption cooling experimental studies, Renew. Sustain. Energy Rev. 65 (2016) 443-458.

[6] D.N. Nkwetta, J. Sandercock, A state-of-the-art review of solar air-conditioning systems, Renew. Sustain. Energy Rev. 60 (2016) 1351-1366. doi:10.1016/j.rser.2016.03.010.

565 [7] I. Sarbu, C. Sebarchievici, Review of solar refrigeration and cooling systems, Energy Build. 67 (2013) 286-297. doi:10.1016/j.enbuild.2013.08.022. 

1126-1140. doi:10.1016/j.renene.2017.06.081.

[9] M. Raisul Islam, K. Sumathy, S. Ullah Khan, Solar water heating systems and their market trends, Renew. Sustain. Energy Rev. 17 (2013) 1-25. doi:10.1016/j.rser.2012.09.011. pumps, Renew. Sustain. Energy Rev. 31 (2014) 681-707. doi:10.1016/j.rser.2013.12.021. technology, Renew. Sustain. Energy Rev. 16 (2012) 5331-5348. doi:10.1016/j.rser.2012.04.049. systems: An updated review, Renew. Sustain. Energy Rev. 44 (2015) 159-181.

[13] A. Ghafoor, A. Munir, Worldwide overview of solar thermal cooling technologies, Renew. Sustain. Energy Rev. 43 (2015) 763-774. doi:10.1016/j.rser.2014.11.073. by the Sun: Reality or Reverie, in: Energy Procedia, The Author(s), 2016: pp. 844-856. feasibility assessment of solar-assisted single-effect, double-effect, and triple-effect absorption 
589 [16] R. Gomri, Investigation of the potential of application of single effect and multiple effect absorption cooling systems, Energy Convers. Manag. 51 (2010) 1629-1636. doi:10.1016/j.enconman.2009.12.039.

[17] S. Suman, M. Kaleem, M. Pathak, Performance enhancement of solar collectors - A review, Renew. Sustain. Energy Rev. 49 (2015) 192-210. doi:10.1016/j.rser.2015.04.087.

[18] Cabrera F J , FernándezGarcía, A, Silva R M P, Use of parabolic trough solar collectors for solar refrigeration and air-conditioning applications, Renew. Sustain. Energy Rev. 20 (2013) 103-118. doi:10.1016/j.rser.2012.11.081.

[19] M.U. Siddiqui, S.A.M. Said, A review of solar powered absorption systems, Renew. Sustain. Energy Rev. 42 (2015) 93-115. doi:10.1016/j.rser.2014.10.014. systems, Energy Convers. Manag. 105 (2015) 403-422. doi:10.1016/j.enconman.2015.07.084.

601 [21] S. Bahria, M. Amirat, A. Hamidat, M. El Ganaoui, M. Slimani, Parametric study of solar heating and cooling systems in different climates of Algeria - A comparison between conventional and high-energy-performance buildings, Energy. 113 (2016) 521-535. system, Energy Convers. Manag. 97 (2015) 243-252. doi:10.1016/j.enconman.2015.03.046.

607 [23] G. Leonzio, Solar systems integrated with absorption heat pumps and thermal energy storages: state of art, Renew. Sustain. Energy Rev. 70 (2017) 492-505. doi:10.1016/j.rser.2016.11.117.

609 [24] A. Shirazi, R.A. Taylor, G.L. Morrison, S.D. White, Solar-powered absorption chillers: A 

doi:10.1016/j.enconman.2018.05.091.

[25] E. Bellos, C. Tzivanidis, Energetic and financial analysis of solar cooling systems with single effect absorption chiller in various climates, Appl. Therm. Eng. 126 (2017) 809-821. doi:10.1016/j.applthermaleng.2017.08.005. thermal cooling systems in different climates, Renew. Energy. 80 (2015) 827-836. doi:10.1016/j.renene.2015.02.019. Combust. Sci. 71 (2019) 81-117. doi:10.1016/j.pecs.2018.11.001. collectors, Int. J. Energy Environ. Eng. 9 (2018) 59-70. doi:10.1007/s40095-017-0255-3. Sol. Energy. 158 (2017) 663-678. doi:10.1016/j.solener.2017.10.038.

624 [30] E. Bellos, C. Tzivanidis, K.A. Antonopoulos, A detailed working fluid investigation for solar parabolic trough collectors, Appl. Therm. Eng. 114 (2017) 374-386.

627 [31] A. Shirazi, R.A. Taylor, G.L. Morrison, S.D. White, A comprehensive, multi-objective doi:10.1016/j.applthermaleng.2016.11.201.

630 [32] Z.Y. Xu, R.Z. Wang, H.B. Wang, Experimental evaluation of a variable effect LiBr-water 
[33] S.C. Kaushik, A. Arora, Energy and exergy analysis of single effect and series flow double 1258. doi:10.1016/j.ijrefrig.2009.01.017.

[34] E. Bellos, C. Tzivanidis, K.A. Antonopoulos, Exergetic, energetic and financial evaluation of a solar driven absorption cooling system with various collector types, Appl. Therm. Eng. 102 (2016) 749-759. doi:10.1016/j.applthermaleng.2016.04.032. chillers, Renew. Energy. 32 (2007) 183-199. doi:10.1016/j.renene.2006.01.018. Experimental and model based performance analysis and design, Sol. Energy. 84 (2010) 166182. doi:10.1016/j.solener.2009.10.010. collectors for office buildings: A case study for Greece, Renew. Energy. 97 (2016) 697-708.

647 [38] J. Wang, R. Yan, Z. Wang, X. Zhang, G. Shi, Thermal Performance Analysis of an Absorption doi:10.1016/j.renene.2016.06.027. Cooling System Based on Parabolic Trough Solar Collectors, Energies. 11 (2018) 2679. doi:10.3390/en11102679. 
653 [40] M. Balghouthi, M.H. Chahbani, A. Guizani, Investigation of a solar cooling installation in Tunisia, Appl. Energy. 98 (2012) 138-148. doi:10.1016/j.apenergy.2012.03.017.

655

656

657

658

659

660

661

662

663

664

665

666

667

668

669

670

671

672

[41] E. Bellos, C. Tzivanidis, S. Pavlovic, V. Stefanovic, Thermodynamic investigation of LiCl$\mathrm{H} 2 \mathrm{O}$ working pair in a double effect absorption chiller driven by parabolic trough collectors, Therm. Sci. Eng. Prog. 3 (2017) 75-87. doi:10.1016/j.tsep.2017.06.005.

[42] A. Shirazi, R.A. Taylor, S.D. White, G.L. Morrison, Transient simulation and parametric study of solar-assisted heating and cooling absorption systems: An energetic, economic and environmental (3E) assessment, Renew. Energy. 86 (2016) 955-971. doi:10.1016/j.renene.2015.09.014.

[43] M.S.A. Khan, A.W. Badar, T. Talha, M.W. Khan, F.S. Butt, Configuration based modeling and performance analysis of single effect solar absorption cooling system in TRNSYS, Energy Convers. Manag. 157 (2018) 351-363. doi:10.1016/j.enconman.2017.12.024.

[44] O. Behar, A. Khellaf, K. Mohammedi, A novel parabolic trough solar collector model Validation with experimental data and comparison to Engineering Equation Solver (EES), Energy Convers. Manag. 106 (2015) 268-281. doi:10.1016/j.enconman.2015.09.045.

[45] P.D. Tagle-Salazar, K.D.P. Nigam, C.I. Rivera-Solorio, Heat transfer model for thermal performance analysis of parabolic trough solar collectors using nanofluids, Renew. Energy. 125 (2018) 334-343. doi:10.1016/j.renene.2018.02.069.

[46] Alberto D L C, Roca L, Bonilla J, Dynamic modeling and simulation of a double-effect absorption heat pump, Int. J. Refrig. 72 (2016) 171-191. doi:10.1016/j.ijrefrig.2016.07.018. 
[47] M. Fan, H. Liang, S. You, H. Zhang, B. Yin, X. Wu, Applicability analysis of the solar heating system with parabolic trough solar collectors in different regions of China, Appl. Energy. 221 (2018) 100-111. doi:10.1016/j.apenergy.2018.03.137.

[48] A.A. Hachicha, I. Rodríguez, R. Capdevila, A. Oliva, Heat transfer analysis and numerical doi:10.1016/j.apenergy.2013.04.067.

[49] Dudley V E, Kolb G J, Mahoney A R, et al. Test results: SEGS LS-2 solar collector. Nasa Sti/recon Technical Report N, 1994, 96(4):2506-2514.

[50] R.V. Padilla, G. Demirkaya, D.Y. Goswami, E. Stefanakos, M.M. Rahman, Heat transfer analysis of parabolic trough solar receiver, Appl. Energy. 88 (2011) 5097-5110. doi:10.1016/j.apenergy.2011.07.012. thesis]. University of South Florida; 2011. performance of parabolic trough solar collectors, Sol. Energy. 95 (2013) 65-78.

691 [54] Churchill S W, Chu H H S . Correlating equations for laminar and turbulent free convection from a vertical plate. Int. J. Heat Mass Transf 1975; 18(11):1323-1329.

693 [55] A. Žukauskas. Heat Transfer from Tubes in Crossflow[J]. Advances in Heat Transfer 1987; 
695 [56] Forristall R. Heat transfer analysis and modeling of a parabolic trough solar receiver implemented in engineering equation solver. NREL/TP-550-34169, 2003.

[57] S.A. Kalogirou, A detailed thermal model of a parabolic trough collector receiver, 2012. doi:10.1016/j.energy.2012.06.023. and $\mathrm{LiBr}-\mathrm{H} 2 \mathrm{O}$ working pairs in a solar absorption cooling system, Energy Convers. Manag. 123 (2016) 453-461. doi:10.1016/j.enconman.2016.06.068.

[59] W. Zheng, J. Yang, H. Zhang, S. You, Simulation and optimization of steam operated double effect water-LiBr absorption heat pump, Appl. Therm. Eng. 109 (2016) 454-465. doi:10.1016/j.applthermaleng.2016.08.113.

[60] Y. Guo, F. Wang, M. Jia, S. Zhang, Modeling of plate heat exchanger based on sensitivity analysis and model updating, Chem. Eng. Res. Des. 138 (2018) 418-432.

[61] Coleman T F, Li Y . On the convergence of interior-reflective Newton methods for nonlinear minimization subject to bounds. Mathematical Programming 1994; 67(1-3):189-224. for residential application in diverse climatic conditions based on 3E analysis, Energy Convers.

713 [63] M. Fan, H. Liang, S. You, H. Zhang, B. Yin, X. Wu, Performance analysis of a solar heating system with the absorption heat pump and oil/water heat exchanger, in: Energy Procedia, 
716 [64] U. Desideri, S. Proietti, P. Sdringola, Solar-powered cooling systems: Technical and economic analysis on industrial refrigeration and air-conditioning applications, Appl. Energy. 86 (2009) 1376-1386. doi:10.1016/j.apenergy.2009.01.011.

[65] A.H. Mosaffa, L.G. Farshi, C.A. Infante Ferreira, M.A. Rosen, Exergoeconomic and environmental analyses of $\mathrm{CO} 2 / \mathrm{NH} 3$ cascade refrigeration systems equipped with different types of flash tank intercoolers, Energy Convers. Manag. 117 (2016) 442-453. doi:10.1016/j.enconman.2016.03.053. China, Energy Convers. Manag. 48 (2007) 654-668. doi:10.1016/j.enconman.2006.05.016. 